\title{
Mathematical modelling of the ensiling process before biogas production: strengthening the links between biomass storage and anaerobic digestion
}

\author{
Ruben Teixeira Franco, Rémy Bayard, Pierre Buffière ${ }^{1}$ \\ Univ Lyon, INSA-Lyon, DEEP Laboratory, EA7429, F-69621 Villeurbanne cedex, \\ France
}

\begin{abstract}
A stoechio-kinetic model describing the evolution of biomass through the ensiling process was developed. The model framework is based on the ADM1 in order to establish a mathematical link between ensiling and anaerobic digestion. Data from ensiling experiments with catch crop and cattle manure were used for model implementation. The model accurately describes the evolution of chemical species under most of storage conditions. Only very few adjusted parameters varied among the tested conditions, notably certain kinetic coefficients. These coefficients depend on the nature and biochemical characteristics of the feedstock. Simulations of the conservation of the biomethane potential were qualitatively consistent with the experimental results. However, additional reactions or inhibitory phenomena should be added to enhance quantitative reliability of this parameter in some cases. Simulations results show that hydrolysis reactions have low kinetic constants during ensiling (0.001-0.012 $\left.\mathrm{d}^{-1}\right)$. Furthermore, different tolerance levels to $\mathrm{pH}$ and dryness among microbial populations were identified. Lactic acid bacteria can proliferate at low $\mathrm{pH}$ and low moisture content. The remaining fermentative microorganisms, such as clostridial bacteria, are more
\end{abstract}

\footnotetext{
' Corresponding author. Tel.: +33(0) 472438478

E-mail addresses: ruben.teixeirafranco@insa-lyon.fr (R. Teixeira Franco), remy.bayard@insa-lyon.fr (R. Bayard), pierre.buffiere@insa-lyon.fr (P. Buffière)
} 
sensitive to low $\mathrm{pH}$ conditions. Moreover, this model illustrates that the conservation of methane potential is positively correlated with the content of easily accessible carbohydrates and total solids in the raw material. This work can be a support tool for the management of resources before anaerobic digestion.

Keywords: Biomass; Ensiling; Anaerobic digestion; Mathematical modelling; Kinetics;

Stoechio-kinetic model

\section{Highlights}

- A stoechio-kinetic model for biomass storage before anaerobic digestion was developed

- ADM1 approach was applied to the anaerobic phase of the ensiling model

- Dynamics of silage compounds, $\mathrm{pH}$ evolution and methane conservation are described

- The model is applicable to the main feedstocks of agricultural AD (manure, crops)

\section{Nomenclature}

AA, amino acids; AC, acetic acid; AD, anaerobic digestion; ADM1, anaerobic digestion model No.1; BA, butyric acid; BC, buffering compounds; BMP, biomethane potential; $\mathrm{CC}$, catch crop; $\mathrm{CH}$, carbohydrates; $\mathrm{CM}$, cattle manure; $\mathrm{COD}$, chemical oxygen demand; DAE, differential and algebraic equation; ET, ethanol; $f_{\text {product,substrate, }}$ product yield on the substrate; $H_{i}$, Henry constant of component $i$; IC, inorganic carbon; $\mathrm{IN}$, inorganic nitrogen; $I_{p H_{-} i}$, inhibition function based on the $\mathrm{pH} ; K_{a}$ dissociation constant; $K_{b}$ association constant; $k_{j}$, rate coefficient of the process $j ; K_{S_{-} i}$, halfsaturation value of biomass that consumes the substrate $i$; LA, lactic acid; LAB, lactic 
acid bacteria; $\mathrm{NH}_{3}-\mathrm{N}$, ammonia nitrogen; $N_{i}$, nitrogen content of component $i ; P_{i}$, partial pressure of component $i$; $p_{M_{-} i}, \mathrm{pH}$ for which the bacterial activity is half the maximum; $q_{i}$, sensitivity of the bacterial activity around the $p_{M_{-} i} ; \mathrm{PR}$, proteins; $S_{i}$, concentration of component $i$ on the soluble phase; SU, sugar degraders; TKN, total Kjeldahl nitrogen; TS, total solids; VFA; volatile fatty acids; VS, volatile solids; WSC, water soluble carbohydrates; $X_{i}$ concentration of component $i$ on the particulate phase; $Y_{i}$, biomass yield on substrate $i ; \rho_{j}$, reaction rate of process $j ; \mu_{\max \_} i$, maximum specific growth rate of biomass.

\section{Introduction}

Society is now confronted with the energy transition, which is considered as an integral part of the solution for the sustainable development of future generations. Anaerobic digestion $(\mathrm{AD})$ is one of the renewable energy production sectors that has attracted increasing interest in recent years. In this process, the bioconversion of complex organic materials is carried out, under anaerobic conditions and by successive reactions. The biogas produced, mainly composed of $\mathrm{CH}_{4}$ and $\mathrm{CO}_{2}$, can be then upgraded and injected into the gas network, converted into electricity or used as transportation fuel. Today, there are more than 17000 biogas plants operating in Europe, including around 12500 agricultural AD plants [1].

One of the major challenges for the optimization of the AD sector concerns the management of feedstocks before biogas production. Indeed, with the need for a continuous supply of $\mathrm{AD}$ plants throughout the year, some seasonal production inputs have to be stored in most cases for extended periods (several months). Since these feedstocks are readily biodegradable, long-term storage can result in significant energy losses and greenhouse gas emissions. 
Ensiling is usually pointed out as the logical choice to preserve the energy potential of wet bio-products in the long term [2]. It relies on the anaerobic conservation through the stabilization of organic matter at acidic pH. Ensiling can be described as follows [3-8]. First, aerobic respiration occurs during several hours, converting water-soluble carbohydrates (WSC) into carbon dioxide, water and releasing energy. Once oxygen is depleted, microorganisms capable of anaerobic growth will compete for the substrate. Under suitable conditions, lactic acid bacteria (LAB), naturally present in wet raw materials, will produce lactate from available carbohydrates, decreasing and stabilizing the $\mathrm{pH}$ to around 4.0. This prevents further microbial activity (lactate degraders: clostridia, acetogens, etc.) and enables the long term preservation of the organic matter. These chemical pathways are illustrated in Table 1. Ensiling is particularly interesting for $\mathrm{AD}$ as it can lead to full preservation of the biomethane potential (BMP) of feedstocks for prolonged durations (that can reach up to 1 year) $[2,7,9-18]$. However, ensiling performance is extremely dependent on the feedstock and its biochemical properties, notably the total solids (TS) level, the amount of accessible carbohydrates, the buffering capacity and the nature of the initial endogenous microflora [3,4]. For instance, even though cattle manure is a major feedstock for agricultural AD it does not naturally lead to an optimal ensiling conservation. In fact, for this feedstock the low acidification degree during confined storage cannot prevent further bacterial activity and spoiling. Therefore, secondary (clostridial) fermentation, acetogenesis and methanogenesis will occur, resulting in vast energy losses. This is especially due to lack of easily fermentable sugars, high moisture content and high methanogenic activity found on this type of substrate $[15,16]$. Co-ensiling with other substrates containing easily accessible carbohydrates and/or low moisture content has been proposed as an 
effective technique to enhance energy conservation of cattle manure during storage $[15,16]$.

The understanding of the biochemical mechanisms that occur during ensiling has been addressed by few authors in modeling approaches $[19,20]$. These studies are mainly based on the lactic and clostridial fermentations phenomena, as well as hydrolysis reactions of the particulate compounds. Nevertheless, these reported modelling works do not include the reactions that take place during inefficient storage (such as acetogenesis and methanogenesis). Also, they are still very far from AD models (e.g. [21-24]) and the logic of conservation of energy potential for biogas production. In order to fill these knowledge gaps, structured models of biomass storage should be developed. They should be applicable for the ensiling of the main feedstocks used in agricultural AD (manure, etc.). Furthermore, they should provide hints about the best storage practices before anaerobic digestion for a given raw material.

In this work, a mathematical model of the ensiling process with a focus on its anaerobic phase was developed. A set of biological reactions and chemical equilibria was used to simulate the temporal variation of the main compounds during storage, including $\mathrm{pH}$. Additionally, BMP preservation was estimated through $\mathrm{CH}_{4}$ and $\mathrm{H}_{2}$ production during ensiling. The model design is based on the mentioned ensiling models $[19,20]$, but with an implementation approach similar to that of Anaerobic Digestion Model No.1 (ADM1) [24]. Degradable chemical oxygen demand (COD) was used as unit. A particular attention has been paid to the fractionation of organic matter (from measurements to state variables). The model implementation was carried out with two different types of feedstock widely used in agricultural AD: catch crops and cattle 
manure. This should validate the applicability of this model framework for a large range of raw materials with different biochemical properties.

Finally, this model is intended to develop a better understanding of methane potential preservation by:

- Describing the main phenomena involved during the ensiling process;

- Investigating both efficient (e.g. energy crops) and inefficient (e.g. manure) feedstocks for ensiling;

- Establishing a mathematical link between biomass storage and anaerobic digestion. This is accomplished by using degradable COD as unit for organic carbon assessment, and estimating the $\mathrm{pH}$ evolution and energy conservation during ensiling.

\section{Experimental trials}

\subsection{Feedstock and co-substrates}

Samples of catch crops and fresh cattle manure were collected from an agricultural site in the Auvergne-Rhône-Alpes region of France (Gaec Béreyziat, Les Teppes, 01340 Béréziat, France). Catch crop was composed by a mixture of sunflower, sorghum, peas, Vicia sp. and Trifolium alexandrinum. In order to assess the impact of TS content, both fresh and dried catch crop were ensiled. Catch crop drying was performed during $96 \mathrm{~h}$ : wilting, i.e., natural drying of organic matter, for $72 \mathrm{~h}$; and then $24 \mathrm{~h}$ on air-ventilated stove at $35^{\circ} \mathrm{C}$. Before storage, fresh cattle manure (10\% of TS content) was mixed with wheat straw (0.10 m maximum length) in order to reach a final TS content of $19 \%$ (ensilable TS level [16]). Cattle manure was ensiled with and without co-substrate addition. Anhydrous glucose (D-(+)-glucose for analysis, Chimie-Plus, France) was 
used as co-substrate and represented around $40 \%$ of volatile solids (VS) content. Conditions of ensiling experiments are summarized in Table 2.

\subsection{Ensiling experiments}

Laboratory trials were performed in $3.5 \mathrm{~L}$ airtight round plastic storage drums. In order to enable biogas output and at the same time minimizing headspace, silos were filled up to $2.55 \mathrm{~L}$ with raw material at packing density of $700 \mathrm{~kg} \cdot \mathrm{m}^{-3}$, the remaining volume being filled with gravel, using a geotextile membrane to separate it from the raw material. Proper plastic lid and rubber ring were used for silo sealing and its airtightness was reinforced with silicone sealant. Then, silos were weighed and placed in a controlled-temperature room at $25 \pm 2{ }^{\circ} \mathrm{C}$. Experiments were conducted during 7, 15, 30 and 120 days for cattle manure and 7, 14, 28 and 98 days for catch crop.

\subsection{Analytical methods}

For each sample time, one silo (per tested condition) was sacrificed. It was opened and weighed. Then, biomass was homogenized and two samples were taken. The first sample was used for direct analyses on the crude material and the other one was mixed with water in order to get two fractions: a water-soluble phase and a particulate phase. This leaching test was performed with a 10:1 water/TS ratio during $2 \mathrm{~h}$ under constant bottle rotation. Phase separation was achieved by centrifugation (5000 G; 10 min) followed by $0.7 \mu \mathrm{m}$ particle size filtration. Finally, the particulate phase was dried at 70 ${ }^{\circ} \mathrm{C}$ until constant weight and ground at $2 \mathrm{~mm}$ theoretical length. Crude material/watersoluble and particulate samples were stored at $4{ }^{\circ} \mathrm{C}$ and $-20^{\circ} \mathrm{C}$, respectively, until analysis. 
Crude material was analyzed for its TS/VS content and BMP. For the water-soluble phase, besides TS/VS content, $\mathrm{pH}$, WSC, volatile fatty acids (VFA), COD, total Kjeldahl nitrogen $(\mathrm{TKN})$ and ammonia nitrogen $\left(\mathrm{NH}_{3}-\mathrm{N}\right)$ fractions were determined. Particulate solid was analyzed for its TS/VS, COD and TKN.

Full description of experimental procedure, including phase separation, methods for chemical analysis and BMP measurement can be found elsewhere [2,15]. It should be mentioned that BMP trials followed the recommendations of the international task group on the standardization of BMP tests [25].

\section{Mathematical model}

\subsection{Units}

Degradable COD $\left(\mathrm{kg}_{\mathrm{COD}} \cdot \mathrm{m}^{-3}\right)$ basis was used for the concentration of chemical compounds because of its flexibility in the study of anaerobic processes, its use in ADM1 [24] and its experimental accessibility to liquid and particulate samples. For inorganic carbon $\left(\mathrm{CO}_{2}\right.$ and $\left.\mathrm{HCO}_{3}{ }^{-}\right)$and inorganic nitrogen $\left(\mathrm{NH}_{4}{ }^{+}\right.$and $\left.\mathrm{NH}_{3}\right) \mathrm{kmol} \cdot \mathrm{m}^{-3}$ was used as unit.

\subsection{Biochemical processes}

\subsubsection{Aerobic phase}

When the silo is sealed, aerobic respiration of organic matter occurs until the oxygen is completely consumed. This is described by the following reaction $[4,20]$ :

$$
\mathrm{C}_{6} \mathrm{H}_{12} \mathrm{O}_{6}+6 \mathrm{O}_{2} \rightarrow 6 \mathrm{CO}_{2}+6 \mathrm{H}_{2} \mathrm{O}
$$

Since this phase only lasts for a few hours, its impact on the evolution of ensiling is negligible while compared to the anaerobic phase. For instance, sugars consumed during respiration were estimated to be less than $2 \%$ of the amount found in ensilable 
raw materials. Therefore, the aerobic phase was not accounted for in the dynamic model. Nevertheless, its effects on some initial conditions $\left(\mathrm{CO}_{2}\right.$ concentration and $\left.\mathrm{pH}\right)$ used to model the anaerobic phase were considered. In fact, since respiration leads to $\mathrm{CO}_{2}$ production and solubilization, the $\mathrm{pH}$ will slightly drop during aerobic phase. In this model it was considered an initial $\mathrm{CO}_{2}$ concentration in the gas phase of $0.038 \%$ $(\mathrm{V} / \mathrm{V})$ and $21 \%(\mathrm{~V} / \mathrm{V})$ at the end of the aerobic phase. The last concentration was calculated considering the exclusive conversion of $\mathrm{O}_{2}$ to $\mathrm{CO}_{2}$ under constant gas pressure (which is the case in our experiments). Then the inorganic carbon dissolved in the liquid phase $\left(S_{I C}\right)$ was calculated according to Henry's law:

$$
S_{I C}=H_{I C} \times P_{I C}
$$

Where the Henry constant for $\mathrm{CO}_{2}\left(H_{I C}\right)$ is $0.035 \mathrm{kmol} . \mathrm{m}^{-3} \cdot \mathrm{bar}^{-1}\left(25^{\circ} \mathrm{C}\right)[24]$ and $P_{I C}$, the partial pressure of $\mathrm{CO}_{2}$, is equal to the total gas pressure (assumed equal to the $\mathrm{P}_{\mathrm{atm}}$ $=1.013$ bar) multiplied by the volume fraction of $\mathrm{CO}_{2}$ in the gas phase.

\subsubsection{Anaerobic phase}

The anaerobic phase of ensiling comprises a large number of reactions that occur either sequentially or in parallel, due to the complexity of the endogenous microflora. In the present model we did not represent all the conceivable biochemical reactions. We rather described the confined storage from the main observable phenomena. The anaerobic model is schematized in Figure 1 and includes the following biochemical reactions:

1. Hydrolysis of particulate carbohydrates into water-soluble sugars;

2. Lactic fermentation of soluble sugars;

3. Clostridial fermentation of lactic acid;

4. Hydrolysis of proteins; 
5. Fermentation of amino acids;

6. Methanogenesis.

These reactions can be separated into extracellular and intracellular mechanisms. The enzymatic/chemical hydrolysis reactions ( 1 and 4$)$ are extracellular and are presumed to follow a first order kinetics, which is a simplification based on empiricism [24]. The reaction rate $\left(\rho_{j}\right)$ of these two reactions is described through Eq. (3:

$$
\rho_{j}=k_{j} \times X_{i}
$$

Where $k_{j}$ is the rate coefficient of the process $j$ and $X_{i}$ is the concentration of the particulate compound $i$.

Fermentation (2, 3 and 5) and methanogenesis (6) are intracellular biochemical reactions that result in both cell growth and decay. Decay was not considered in the present work, since its impact was found negligible (results not shown). Thus, the biological kinetics are described by the consumption of the substrate and growth of the biomass. These biological reactions are presented according to a Monod kinetics based on the consumption of the substrate:

$$
\rho_{j}=\frac{X_{i} \times \mu_{\text {max }_{\_} i}}{Y_{i}} \times \frac{S_{i}}{K_{S_{-} i}+S_{i}} \times I_{p H_{-} i}
$$

Where, $X_{i}$ is the concentration of biomass that consume the substrate $i, \mu_{\text {max }} i$ the maximum specific growth rate of biomass, $Y_{i}$ the biomass yield on the substrate $i, S_{i}$ the concentration of substrate $i$ and, $K_{S_{-} i}$ the half-saturation value of biomass that consumes the substrate $i$. The term $I_{p H_{-} i}$ reflects an inhibition mechanism based on the $\mathrm{pH}$ of the medium. The use of such biological inhibition is mandatory in this type of kinetic model 
since biomass growth and substrate consumption only occur when the $\mathrm{pH}$ of the silage is above a critical value. This function is represented by the following equation [19]:

$$
I_{p H_{-} i}=\frac{\left(p H / p_{M_{-} i}\right)^{q_{i}}}{1+\left(p H / p_{M_{-} i}\right)^{q_{i}}}
$$

Where, $p_{M_{-} i}$ describes the $\mathrm{pH}$ for which the activity is half the maximum and $q_{i}$ is the sensitivity of the activity around $p_{M_{-} i}$. The sensitivity of the inhibition function to these two parameters is presented in Figure 2.

The rate equations for the biochemical processes of the anaerobic phase model are detailed in Table 3. This is presented as a Güjer matrix, which has an implicit COD balance. In this table, the stoichiometry of the reactions is presented as product yield on the substrate $\left(f_{\text {product,substrate }}\right)$. In addition, the acid/base pairs are presented as the sum of the concentrations of the acid and base forms (e.g. $\left.S_{I C}=S_{\mathrm{CO} 2}+S_{\mathrm{HCO} 3}\right)$. Since neither inorganic carbon nor inorganic nitrogen has COD, these compounds have been implemented with a molar base conversion. For example, in the case of clostridial fermentation, the conversion of organic carbon was carried out knowing that the biodegradation of $1 \mathrm{~g}_{\mathrm{COD}}$ of lactate produces 1/64 moles of inorganic carbon (not counting the bacterial yield). For inorganic nitrogen, a conversion based on the nitrogen molar content of the amino acids $\left(\mathrm{N}_{\mathrm{AA}}\right)$ was applied.

This representation includes several assumptions made in order to simplify the system and its determination from experimental measurements:

- The fraction of easily accessible carbohydrates includes not only soluble monosaccharides, but also a portion of non-structural particulate compounds such as starch. The hydrolysis reactions of the latter are not considered to be a limiting 
factor and, subsequently, were not added to the model. For the fraction of hardly accessible sugars, mainly the structural compounds (hemicellulose and cellulose) were considered.

- Acetic acid is used as a model molecule for other minor VFA formed during storage (propionic, valeric, caproic and formic acids). This may lead to differences in the by-products formed and in the $\mathrm{pH}$ evolution.

- Each fermentation process is represented by a general reaction, catalyzed by a single bacterial trophic group. For instance, in the case of lactic fermentation, a homofermentative reaction was used for the production of both lactic acid and ethanol (by applying stoichiometric coefficients). However, since the production of ethanol is theoretically carried out by hetero-fermentative bacteria, this leads to some inaccuracy with respect to the production of other by-products such as $\mathrm{CO}_{2}$. In the same way, for the consumption of lactic acid, a single trophic group (clostridial bacteria) was supposed to carry out the production not only of butyric acid, but also of acetic acid, so as to consider both other minority VFA and a possible acetogenesis reaction. This assumption underestimates the energy losses due to $\mathrm{H}_{2}$ production and may lead to deviations in the $\mathrm{pH}$ value.

- Biodegradation reactions of ethanol and butyric acid were not taken into account, which can lead to imprecisions for inefficient silages.

- The inorganic nitrogen consumed for bacterial growth was assumed negligible and was not included in the nitrogen balance.

- Since the silos were regularly degassed, the closed system equilibrium model was not compatible with the experiments. Therefore, this equilibrium was not incorporated in the anaerobic model. However, this leads to the total solubilization 
of $\mathrm{CO}_{2}$ produced. This issue is discussed in further detail in section 3.4. Model implementation.

\subsection{Physicochemical processes}

The prediction of the $\mathrm{pH}$ is a crucial point for the ensiling process. The $\mathrm{pH}$ is a result of acid-base equilibria of the different chemical species in the system. In this model, it were considered the equilibrium reactions of the important compounds in ensiling with $\mathrm{pK}_{\mathrm{a}}$ values (Table 4 ) close to the operating $\mathrm{pH}$ of this process. This included the following acid-base pairs: $\mathrm{HLA} / \mathrm{LA}^{-} ; \mathrm{HBA} / \mathrm{BA}^{-} ; \mathrm{HAC} / \mathrm{AC}^{-} ; \mathrm{NH}_{4}^{+} / \mathrm{NH}_{3} ; \mathrm{CO}_{2} /$ $\mathrm{HCO}_{3}{ }^{-}$and $; \mathrm{H}_{2} \mathrm{O} /\left(\mathrm{OH}^{-}+\mathrm{H}^{+}\right)$. These reactions constitute a set of algebraic equations which were integrated in the model by a charge balance.

So that the acid-base phenomena can be modeled as implicit algebraic equations, for each reaction the sum of the acid-base pair concentrations was considered as a dynamic state variable, as shown in the following equations:

$$
\begin{gathered}
S_{L A}-S_{L A-}-S_{H L A}=0 \\
S_{B A}-S_{B A-}-S_{H B A}=0 \\
S_{A C}-S_{A C-}-S_{H A C}=0 \\
S_{I C}-S_{H C O 3-}-S_{C O 2}=0 \\
S_{I N}-S_{N H 3}-S_{N H 4+}=0
\end{gathered}
$$

Where, for example in equation $6, S_{L A}$ is the acid-base pair combination, $S_{H L A}$ is the associated form and $S_{L A-}$ is the dissociated form. Thus, these algebraic equations can be formulated considering the acid-base equilibrium and the equilibrium constants (Table 4) respectively:

$$
S_{L A-}-\frac{K_{a_{-} L A} S_{L A}}{K_{a_{-} L A}+S_{H+}}=0
$$




$$
\begin{gathered}
S_{B A-}-\frac{K_{a_{\_} B A} S_{B A}}{K_{a_{-} B A}+S_{H+}}=0 \\
S_{A C-}-\frac{K_{a_{\_} A C} S_{A C}}{K_{a_{-} A C}+S_{H+}}=0 \\
S_{H C O 3-}-\frac{K_{a_{-} C O 2} S_{I C}}{K_{a_{-} \mathrm{CO} 2}+S_{H+}}=0 \\
S_{N H 4+}-\frac{S_{H+} S_{I N}}{K_{a_{-} N H 4+}+S_{H+}}=0
\end{gathered}
$$

The ionic equilibrium of water is also described by the following relation:

$$
S_{\mathrm{OH}-}-\frac{K_{a_{-} H_{2} 0}}{S_{H+}}=0
$$

Then, the concentration of the $\mathrm{H}^{+}$ions and the $\mathrm{pH}$ were calculated using a charge balance with the main species present during ensiling:

$$
\sum S_{C^{+}}-\sum S_{A^{-}}=0
$$

Where $\sum S_{C^{+}}$and $\sum S_{A^{-}}$correspond to the total concentrations of cationic and anionic equivalents, respectively. The equivalent concentration of each ion is its valence multiplied by the molar concentration [24]. Since organic acids were expressed on a COD basis, a conversion of its content in grams of COD per charge was applied in the denominators of the equation. The charge balance with all the ions used in the model is represented by the following equation:

$$
S_{B C+}+S_{N H 4+}+S_{H+}-S_{H C O 3-}-\frac{S_{L A-}}{96}-\frac{S_{B A-}}{160}-\frac{S_{A C-}}{64}-S_{O H-}-S_{B C-}=0
$$

In the above equation $S_{B C+}$ and $S_{B C-}$ are the acid and base concentrations, respectively, of the buffer compounds of the system. These compounds represent acids and bases present in the raw material that do not have terms of consumption or production and, 
thereafter, are assumed to be constant throughout storage. These terms may also include other unmeasured organic acids or proteins and derived products, assuming that they are not degraded during ensiling.

For the calculation of the basic and acidic buffer concentrations, the Neal and Thornley [19] approach was used. This hypothesis considers that association and dissociation are mutually exclusive properties of the buffer. The difference $S_{B C-}-S_{B C+}$ is given by the relation below as described by Neal and Thornley [19]:

$$
S_{B C-}-S_{B C+}=\frac{S_{B C}\left(K_{a_{\_} B C} K_{b_{-} B C}-S_{H+}{ }^{2}\right)}{\left(S_{H+}+K_{a_{-} B C}\right)\left(S_{H+}+K_{b_{-} B C}\right)-S_{H+} K_{a \_B C}}
$$

Where $S_{B C}$ refers to the initial molar concentration of the buffer compounds, $K_{a_{-} B C}$ is the dissociation constant of the acid compounds of the buffer and $K_{b_{-} B C}$ is the association constant of the basic compounds of the buffer.

\subsection{Model implementation}

\subsubsection{Sequential modelling}

In order to be able to solve the model of the anaerobic phase with the charge balance, two preliminary steps have been carried out, namely:

- Estimation of properties of the buffer compounds and;

- Determination of $\mathrm{pH}$ after the aerobic phase.

According to Eq. (19), the buffer compounds $\left(S_{B C-}\right.$ and $\left.S_{B C+}\right)$ are defined by their initial concentration $\left(S_{B C}\right)$ and its dissociation/association constants $\left(K_{a_{-} B C}\right.$ and $\left.K_{b_{-} B C}\right)$. To reduce the number of variables to be estimated, Neal and Thornley's hypothesis [19] of consider $K_{a_{-} B C}=K_{b_{-} B C}$ was performed. Then, the difference $S_{B C-}-S_{B C+}$ was calculated with the charge balance at $\mathrm{t}=0$. Values of $S_{B C}$ and $K_{a_{-} B C} / K_{b_{-} B C}$ were finally 
refined with the charge balance by comparing the simulations results to the experimental decrease of $\mathrm{pH}$ during initial lactic acid production (7 days). This approach can also be considered as an indirect measure of silage buffering capacity, which is often estimated as the amount of base needed to, e.g., vary the $\mathrm{pH}$ from 4 to 6 . The $\mathrm{pH}$ after aerobic respiration was determined by applying the charge balance with the previously estimated buffer properties. The only change made was to consider the increase in the $\mathrm{CO}_{2}$ content in the gaseous phase from $0.038 \%(\mathrm{~V} / \mathrm{V})\left(S_{I C}=1.35 \times 10^{-5}\right.$ kmol.m $\left.\mathrm{m}^{-3}\right)$ initially up to $21 \%(\mathrm{~V} / \mathrm{V})\left(S_{I C}=7.45 \times 10^{-3} \mathrm{kmol} . \mathrm{m}^{-3}\right)$ after respiration.

After these preliminary calculations, the anaerobic phase of the ensilage was simulated through the implementation of the dynamic model on MATLAB ${ }^{\mathrm{TM}}$. Differential and Algebraic Equation (DAE) implementation was used so that physicochemical processes can be integrated algebraically. Since ensiling is a batch process, the model was implemented in the following configuration:

- 16 differential equations to represent dynamic state variables, according to the Güjer matrix (Table 3) and exemplified below for both hardly accessible carbohydrates (Eq. (20)) and inorganic carbon (Eq. (21)).

$$
\begin{gathered}
\frac{d X_{C H}}{d t}=-k_{1} X_{C H} \\
\frac{d S_{I C}}{d t}=\frac{\left(1-Y_{L A}\right)}{96} \frac{X_{L A} \mu_{m a x_{-} L A}}{Y_{L A}} \frac{S_{L A}}{K_{S_{-} \mathrm{LA}}+S_{L A}} \frac{\left(p H / p_{M_{-} \mathrm{LA}}\right)^{q_{L A}}}{1+\left(p H / p_{M_{-} \mathrm{LA}}\right)^{q_{L A}}} \\
+\frac{\left(1-Y_{A C}\right)}{64} \frac{X_{A C} \mu_{m a x_{-} \mathrm{AC}}}{Y_{A C}} \frac{S_{A C}}{K_{S_{-} \mathrm{AC}}+S_{A C}} \frac{\left(p H / p_{M_{-} \mathrm{AC}}\right)^{q_{A C}}}{1+\left(p H / p_{M_{-} \mathrm{AC}}\right)^{q_{A C}}}
\end{gathered}
$$

- 1 algebraic equation that gathers all the physicochemical phenomena for the calculation of $\mathrm{pH}($ Eq. (22)). 


$$
\begin{aligned}
S_{H+}+\frac{S_{H+}}{S_{I N}}-\frac{K_{a_{-} C O 2} S_{I C}}{K_{a_{-} N H 4+}}+\frac{S_{H+}}{K_{a_{-} C O 2}+S_{H+}}-\frac{K_{a_{-} L A} S_{L A}}{\left(K_{a_{-} L A}+S_{H+}\right) \times 96} \\
-\frac{K_{a_{-} B A} S_{B A}}{\left(K_{a_{-} B A}+S_{H+}\right) \times 160}-\frac{K_{a_{\_} A C} S_{A C}}{\left(K_{a_{\_} A C}+S_{H+}\right) \times 64}-\frac{K_{a_{\_} H_{2} O}}{S_{H+}} \\
-\frac{S_{B C}\left(K_{a_{\_} B C} K_{b_{-} B C}-S_{H+}{ }^{2}\right)}{\left(S_{H+}+K_{a_{-} B C}\right)\left(S_{H+}+K_{b_{-} B C}\right)-S_{H+} K_{a_{-} B C}}=0
\end{aligned}
$$

Since this anaerobic model does not take into account the liquid-gas equilibrium, $S_{I C}$ balance (Eq. (21)) considers that all the inorganic carbon produced remains solubilized. To avoid significant impacts on the $\mathrm{pH}$, it was assumed that the partial pressure of $\mathrm{CO}_{2}$ in the gas phase cannot exceed 1 bar, which corresponds to a maximum $S_{I C}$ of $3.50 \mathrm{x}$ $10^{-2} \mathrm{kmol} \cdot \mathrm{m}^{-3}\left(25^{\circ} \mathrm{C}\right)$. This has been integrated into the model by the following condition:

$$
\frac{d S_{I C}}{d t}=\left\{\begin{aligned}
\text { Eq. } 21, & S_{I C}<0.035 \mathrm{kmol} . \mathrm{m}^{-3} \\
0, & S_{I C} \geq 0.035 \mathrm{kmol} . \mathrm{m}^{-3}
\end{aligned}\right.
$$

Even so, the accumulation rate of inorganic carbon in the liquid phase will be greater in the model than in reality. This difference was neglected since silos normally have small headspace and consequently, the $\mathrm{CO}_{2}$ concentration in the gas phase rapidly increases and stabilizes in the first weeks of ensiling.

Finally, it is important to notice that this model was developed to work at constant temperature. Simulations in this study were performed for a standard temperature of 25 ${ }^{\circ} \mathrm{C}$ (the same used in experimental trials).

\subsubsection{From measurements to state variables}

In order to setup the anaerobic model, values of state variables were estimated as follows (initial values are presented in Table 5):

- $\quad X_{C H}$ and $X_{P R}$ : The COD of the particulate phase was measured, as well as its biodegradable fraction (from the BMP tests). However, these analysis do not make 
it possible to distinguish each biodegradable fraction from the particulate COD. As a result, it was assumed that all the COD of the particulate phase corresponded to biodegradable proteins and sugars. This is an assumption that has no practical impact: during ensiling, the bio-accessible particulate fraction is never completely metabolized. Thus, $X_{P R}$ was estimated from the $\mathrm{TKN}_{\text {particulate }}$ measurement (using the $N_{A A}$ parameter) and the $X_{C H}$ was determined by the difference between the $\mathrm{COD}_{\text {particulate }}$ and the $X_{P R}$. Since in the majority of the trials there was a solubilization of the readily available particulate at the beginning of storage, the initial $X_{C H}$ and $X_{P R}$ were determined by extrapolation of the hydrolysis trend for the experimental points from 7 days of silage. However, this approach should not be used for lipidrich feedstocks, which are poorly soluble in water. Under these conditions, an experimental determination of the lipid compounds must be carried out. Nevertheless, the feedstocks studied here have been supposed to have very low fat content.

- $S_{C H}$ : The experimental determination of this variable was not totally possible, since for this parameter only monosaccharides were analyzed by HPLC. For this reason, the initial $S_{C H}$ was estimated as the required amount of sugars for VFA formation in the first week of ensiling. For all other points, it was assumed that only the soluble sugars analyzed remained in the $S_{C H}$ fraction.

- $S_{L A}, S_{E T}, S_{B A}, S_{A C}$ : Calculated from HPLC data and gas chromatography after conversion to COD. It is important to note that $S_{A C}$ includes the COD of acetic, propionic, valeric, caproic and formic acids.

- $S_{A A}$ : This parameter cannot be reliably compared to the results of soluble organic nitrogen $\left(\mathrm{NTK}_{\text {soluble }}-\mathrm{NH}_{3}-\mathrm{N}\right)$, since it was experimentally observed that some of the 
amino acids present are not degradable under ensiling conditions. Therefore, the evolution of this variable was not compared to the experimental results. Its initial value was estimated as the amount needed to simulate the fast production of inorganic nitrogen $\left(S_{I N}\right)$ during the first few weeks of ensiling.

- $S_{I N}$ : Calculated from ammonia $\left(\mathrm{NH}_{3}-\mathrm{N}\right)$ analysis in the liquid phase.

- $S_{I C}, S_{H 2}$ and $S_{C H 4}$ : Initially, $S_{I C}$ was calculated from the $\mathrm{CO}_{2}$ gas content after respiration, while for $S_{H^{2}}$ and $S_{\mathrm{CH}_{4}}$ it was assumed a zero concentration at $\mathrm{t}=0$. On the other hand, the model outputs were not compared with the experimental results, given the insufficient measurements of gas composition and the poor gas production.

- $X_{S U}, X_{L A}, X_{A A}, X_{A C}$ : None of the measurements performed allowed a quantitative determination of the concentration of active biomass. As a result, these variables were estimated from bibliographic data. The value of $0.1 \mathrm{~kg}_{\text {biomass }} \cdot \mathrm{m}^{-3}$ estimated by Neal and Thornley [19] for lactic acid bacteria was used for all the bacterial populations in the fresh material of each feedstock tested in this model. This value was converted to $\mathrm{COD}$ using the empirical formula for biomass $\mathrm{C}_{5} \mathrm{H}_{7} \mathrm{O}_{2} \mathrm{~N}$ proposed by the ADM1 model [24] $\left(\mathrm{M}=113 \mathrm{~kg} \cdot \mathrm{kmol}^{-1}, \mathrm{COD}=160 \mathrm{~kg} \cdot \mathrm{kmol}^{-1}\right)$.

- $\mathrm{S}_{\mathrm{H}+}(\mathrm{pH})$ : For the starting point, the $\mathrm{pH}$ after aerobic respiration was determined and used as initial value for the simulation.

\subsubsection{Kinetic parameters}

For stoichiometric and kinetic parameters, when possible, values from bibliography $[19,24]$ were used and then optimized during the simulations. This was the case for the yields of the product on the substrate, the parameters $p_{M_{-} i}$ and $q_{i}$ for the inhibition functions and the maximum specific growth rates of Monod reactions $\left(\mu_{\max \_} i\right)$. For the 
nitrogen content of proteins and amino acids $\left(N_{A A}\right)$, the value of $0.007 \mathrm{kmol} \cdot \mathrm{kg}_{\mathrm{COD}}{ }^{-1}$ suggested by the ADM1 model [24] was used. Similarly, biomass yields were estimated from literature data ([19] for $Y_{S U}, Y_{L A}$ and $Y_{A A}$, [24] for $Y_{A C}$ ). In contrast, since the kinetic constants of hydrolysis $\left(k_{j}\right)$ (storage conditions) cannot be compared with those used to simulate anaerobic digestion (biogas production conditions), their values were estimated from the biodegradation rates of experimental $X_{C H}$ and $X_{P R}$ particulate fractions during storage. Finally, according to the literature $[19,26]$, the half-saturation values of Monod kinetics are very low and, therefore, have negligible impacts on the simulation results. In the present case, a value of $0.1 \mathrm{~kg}_{\mathrm{COD}} \cdot \mathrm{m}^{-3}$ was used for all the reactions where this parameter is involved. Kinetic and stoichiometric parameters set according to literature data are summarized in Table 6. Optimized parameters during simulations are further described in section 5. Suggested model parameters and discussion.

\section{Simulations and comparison with experimental results}

The simulation were performed for the input variables of different feedstocks in order to calibrate the stoichiometric and kinetic parameters of the model. This included different moisture contents, soluble carbohydrates and initial $\mathrm{pH}$ (Table 2). The simulations were run until the end of ensiling experiments, i.e. 98 days for catch crop and 120 days for cattle manure (at $\left.25^{\circ} \mathrm{C}\right)$.

\subsection{Hardly accessible fractions}

The results of simulations for hardly accessible fractions $\left(X_{C H}\right.$ and $\left.X_{P R}\right)$ are shown in Figure 3. The estimated data followed a slow first order degradation during silage and as a result the model was properly fitted to the variables $X_{C H}$ and $X_{P R}$. 


\subsection{Easily accessible fractions}

Experimental trends for readily accessible COD $\left(S_{C H}, S_{L A}, S_{B A}, S_{A C}\right.$ and $\left.S_{E T}\right)$ during ensiling (Figure 4) are, in their majority, well described by the simulation after calibration of kinetic and stoichiometric parameters (detailed in section 5. Suggested model parameters and discussion).

Still, for some variables there is a gap between the evolution of the model predictions and experimental results. Indeed, the simulation for CM-Glucose condition forecasts an accumulation of easily accessible sugars, due to the hydrolysis reaction. However, this was not observed experimentally. Since the $S_{C H}$ measured during ensiling includes only soluble sugars, this difference indicates that the sugars produced during hydrolysis would remain in the accessible particulate fraction. In addition, ethanol produced during the storage of catch crop is degraded in the long term. This was not accounted for in the simulations, as this reaction was not considered in the model design. Finally, for the worst ensilable feedstock - CM-Fresh - it was observed experimentally a total loss of easily degradable compounds. This is the case, e.g., of butyric acid, which does not accumulate during storage since it is rapidly consumed. However, this phenomenon cannot be described by the simulations, since the model does not include any direct acetogenesis reactions.

\subsection{Inorganic nitrogen}

In most storage conditions the model allows the representation of inorganic nitrogen evolution for a given content of accessible amino acids (Figure 5). On the one hand, the modelling results suggest that there is a large amount of $S_{A A}$ in catch crop. This compounds are degraded in $S_{I N}$ when there is not a strong acidity. On the other hand, cattle manure does not have a significant amount of accessible amino acids. Therefore, 
it is the slow mineralization of the proteins that leads to the slight increase of inorganic nitrogen content. In addition, experimental $S_{I N}$ content of CM-Fresh decreased between 30 and 120 days of ensiling, while the model predicted a slight increase for this variable. This discrepancy might be explained by a partial volatilization and loss of the inorganic nitrogen (given the high $\mathrm{pH}$ ), which has not been taken into account in the model. Finally, the evolution of the experimental inorganic content for CC-Wilted was not correctly modeled. In fact there was a huge increase in the $S_{I N}$ content in the first 7 days of this experiment, which can not only be attributed to the phenomena embedded in the model.

\section{4. $p H$}

Generally speaking, since many chemical species affect the charge balance and consequently the $\mathrm{H}^{+}$ion concentration, $\mathrm{pH}$ is one of the most difficult parameters to predict. Nevertheless, the modelling of this algebraic variable was a great success in most of the cases tested (Figure 6). This was partly due to the use of the buffer capacity of the system. Moreover, the efficiency of these simulations was strictly related to the stability of the organic matter. In fact, for silages without clostridial development - CCWilted and CM-Glucose $-\mathrm{pH}$ variations are perfectly described by the model. Conversely, for fresh cattle manure (CM-Fresh) significant differences between measured $\mathrm{pH}$ and simulations were observed, especially in the first weeks of ensiling. This inconsistency can be explained by the difficulties in simulating the VFA evolution under acetogenic and methanogenic conditions.

\subsection{BMP conservation}

Since COD was chosen as unit of the model and degradation reactions take place under anaerobic conditions, COD loss only occurs through the gas phase. Therefore, simulated 
BMP conservation for a given storage duration $\left(\% B M P_{\text {conserved }, t}\right)$ was calculated from the cumulative production of hydrogen and methane, according to the following equation:

$$
\% B M P_{\text {conserved }, t}=1-\frac{S_{C H 4, t}+S_{H 2, t}}{C O D_{\text {degradable }, i}}
$$

Where $S_{C H 4, t}$ and $S_{H 2, t}$ designate, respectively, the cumulative productions of methane and hydrogen at time $t\left(\mathrm{~kg}_{\mathrm{COD}} \cdot \mathrm{m}^{-3}\right)$ and $C O D_{\text {degradable }, i}$ represents the degradable COD of raw material under anaerobic digestion conditions, obtained from BMP and COD analysis.

The simulations for the conservation of BMP are qualitatively consistent with the experimental results (Figure 7). This indicates that this model can provides hints on the best storage practices to preserve the energy potential of different feedstocks before anaerobic digestion. However, the results show that in some cases it is very difficult to obtain a reliable quantitative estimation of BMP preservation from COD losses by $\mathrm{H}_{2}$ and $\mathrm{CH}_{4}$ production. For certain conditions, this should be due to the fact that during ensiling some gains in bioavailability may occur (due to further hydrolysis of the inaccessible fractions $[3,16,18])$, which has not been integrated into the model. In addition, when the ensiling is very inefficient, namely for CM-Fresh, the preservation of the BMP is overestimated by the simulations. This can partly be explained by the omission of the biodegradation reactions of butyric acid in the model.

\section{Suggested model parameters and discussion}

The results of the simulations were obtained by varying only a limited number of parameters (Table 7), i.e. kinetic constants and stoichiometry, which illustrates the robustness of the model. 
Regarding the stoichiometric coefficients, only one part varied according to the type of feedstock used. Homo-fermentative LAB populations dominated during ensiling, but this was more evident for cattle manure, for which no ethanol was produced during storage. In addition, during clostridial fermentation the yield of butyric acid was lower with cattle manure. This may suggest that the activity of acetogenic populations is greater in cattle manure. In contrast, identical stoichiometric yields of proteolytic fermentation were found for both raw materials.

Hydrolysis reactions had very low kinetic constants, which expresses the fact that ensiling is above all a method of organic matter preservation. Kinetic constant of protein hydrolysis was higher during storage of catch crop and with low TS levels. This may be related not only to the greater enzyme activity with higher moisture content, but also to the degradation of proteolytic enzymes during drying. Nevertheless, this moisture effect was not observed for trials with cattle manure. This may be due to the fact that a limited range of TS content was used. Concerning the degradation of structural carbohydrates, kinetic coefficient varied for all storage conditions and it was not possible to establish any correlation (either with respect to the feedstock type, TS content or level of accessible carbohydrates). On the one hand, this can be linked to inaccuracies in the estimation of the real fraction of carbohydrates, which are difficult to access experimentally. On the other hand, it may not be conceivable to obtain a trend by using a simple first order reaction, given the variety of anaerobic mechanisms that can lead to the hydrolysis of complex sugars. Indeed, the conversion of these polymers under ensiling conditions can be, according to Dewar et al. [27] and McDonald et al. [4] catalyzed either enzymatically or chemically (depending, e.g., on the $\mathrm{pH}$ level). 
Maximum specific growth rates of microorganisms in Monod equations varied among the tested conditions. For lactic acid bacteria, it decreased slightly with the TS increase in both raw materials. For instance, the increase of TS content of catch crop from $10 \%$ to $39 \%$ resulted in a decrease of about $10 \%$ in $\mu_{\max }$. This same TS variation led to a reduction of almost $30 \%$ in the maximum specific growth rate of clostridial bacteria. These results show that the growth of these two bacterial populations is dependent on the TS content. Also, the sensitivity to water availability was much higher for clostridial bacteria, which is why it is preferable to use higher TS content in silage to achieve low $\mathrm{pH}$ stability. This is in line with data found in literature suggesting that different levels of tolerance to dryness are noticed among the silage microorganisms $[3,4,28]$, which is also the case for other anaerobic environments [29,30]. For cattle manure, the sensitivity of clostridial bacteria to the water content could not be verified for the conditions tested. In fact, for Fresh CM simulations the accurate value of $\mu_{\max }$ of clostridial bacteria could not be calculated because the reaction took place before the first sampling. As with previous populations, when methanogenesis reactions occurred during silage, it was possible to identify an increase in $\mu_{\max }$ of methanogenic bacteria at lower TS levels. On the other hand, it was not possible to establish a general correlation for the $\mu_{\max }$ of proteolytic bacteria. Indeed, for catch crop there was an increase in proteolytic activity at higher TS concentrations, whereas for cattle manure no trend was observed among the TS contents tested. Nevertheless, according to the literature $[28,31,32]$, a decrease in proteolytic bacterial activity is also expected for lower moisture levels. This deviation from the literature may be due to the fact that the available amino acid content was estimated from inorganic nitrogen production during silage, certainly having a significant associated error. Finally, it is also important to note that no comparison 
between the values of $\mu_{\max }$ of catch crop and cattle manure was done. In fact, they depend on the amount of initial active biomass, which was arbitrarily set for each feedstock from literature data.

Among the remaining parameters for which identical values were used for all storage conditions, the $\mathrm{pH}$ inhibition function $I_{p H}$ showed interesting results (Figure 8). Indeed, the model suggests that $\mathrm{LAB}$ were not inhibited over most of the $\mathrm{pH}$ range tested, because of their low half-inhibition $\mathrm{pH}\left(\mathrm{p}_{\mathrm{M}, \mathrm{SU}}=4.3\right)$ and the high sensitivity of their activity around this value $\left(\mathrm{q}_{\mathrm{SU}}=35\right)$. This sensitivity also implies that, for $\mathrm{pH}$ values below 4.3, the lactic activity is very reduced, which explains the partial conservation of easily accessible sugars during CM-Glucose experiment. For the other biological reactions, the half-inhibition $\mathrm{pH}$ values used were 5.5 for clostridial and proteolytic fermentations and 7.0 for methanogenesis. Since for these three reactions the sensitivity around these $\mathrm{pH}$ values is also high, this inhibition function mathematically explains the delay in the growth of these bacterial populations for properly acidified silages. Moreover, this evidences that methanogens are more sensitive to low $\mathrm{pH}$ conditions than other fermentative microorganisms [33].

The results of the simulations also showed that this model can describe in a very correct way silages where lactic fermentation proliferates and dominates. However, when one advances on the chain of fermentation reactions (acidogenesis, methanogenesis), the simulations are less efficient. In fact, the model is simplified at the level of acetogenesis and methanogenesis and, consequently, these phenomena cannot be described quantitatively. This means that, in its current form, the model can be used to expose the evolution of ensiling of other types of feedstocks that have, at least, a high accessible sugar content, such as energy crops, forages, or sugar-rich agro-industrial waste. On the 
contrary, for inefficient inputs such as single-handedly cattle manure, this model may only be used to indicate that silage will be ineffective, that there will be substantial energy losses and that it will be necessary to intervene on the initial characteristics of these feedstocks to improve the performance of BMP preservation (for instance, by adding easily biodegradable sugars [15]).

In addition, the model allows a qualitative estimation of the suitable conditions for preserving the energy potential of feedstocks. Indeed, it is shown that the conservation of methane potential is positively correlated with the content of easily accessible carbohydrates and total solids in the raw material. Nevertheless, quantitatively there are still differences between some simulations and the experimental results. For very inefficient storages, this can again be due to the simplification of the model in the final stages of anaerobic digestion. At the same time, for some conditions there are hydrolysis phenomena that may lead to bio-accessibility gains, which are not taken into account in the model.

\section{Conclusions}

A mathematical link was established between biomass storage and anaerobic digestion. This soechio-kinetic model explained the main biochemical phenomena that occur during ensiling, including the evolution of $\mathrm{pH}$ and methane potential. The model framework is applicable for the main feedstocks used in agricultural anaerobic digestion (manure, crops). Therefore, this model can be a crucial support tool for the management of resources before anaerobic digestion. Since storage practices have an important impact on the conservation of the energy content of biomass, this work should contribute to optimize the performance of agricultural biogas plants. 


\section{Acknowledgements}

Ruben Teixeira Franco held a doctoral fellowship from the Rhône-Alpes region. This work has been undertaken within the SAM project (Stockage Avant Méthanisation Storage Before AD) funded by ADEME (\# 1506C0038). The authors thank the DEEP laboratory team, including David Lebouil, Hervé Perier-Camby, Nathalie Dumont and Richard Poncet for the given support during the tests. We are grateful to Franck Barra for his permanent availability for discussion and raw material supply. Mathilde Hardier and SUEZ are also acknowledged for the inoculum provided for the BMP tests.

\section{References}

[1] European Biogas Association, 6th Edition of the Statistical Report of the European Biogas Association, 2016.

[2] R. Teixeira Franco, P. Buffière, R. Bayard, Optimizing storage of a catch crop before biogas production: impact of ensiling and wilting under unsuitable weather conditions, Biomass and Bioenergy. 100 (2017) 84-91. doi:10.1016/j.biombioe.2017.03.017.

[3] R. Teixeira Franco, P. Buffière, R. Bayard, Ensiling for biogas production: Critical parameters. A review, Biomass and Bioenergy. 94 (2016) 94-104. doi:10.1016/j.biombioe.2016.08.014.

[4] P. McDonald, A.. Henderson, S.J.. Heron, The Biochemistry of Silage, Second Edi, Chalcombe Publications, Marlow, Bucks, 1991.

[5] R. Egg, C. Coble, C. Engler, D. Lewis, Feedstock storage, handling and processing, Biomass and Bioenergy. 5 (1993).

[6] Z.G. Weinberg, G. Ashbell, Engineering aspects of ensiling, Biochem. Eng. J. 13 (2003) 181-188. 
[7] C. Herrmann, M. Heiermann, C. Idler, Effects of ensiling, silage additives and storage period on methane formation of biogas crops, Bioresour. Technol. 102 (2011) 5153-5161. doi:10.1016/j.biortech.2011.01.012.

[8] E. Zimmer, Efficient silage systems, in: C. Thomas (Ed.), Forage Conserv. 80’s, British Grassland Society, Brighton, UK, 1980: pp. 186-197.

[9] S. Liu, X. Ge, L.N. Liew, Z. Liu, Y. Li, Effect of urea addition on giant reed ensilage and subsequent methane production by anaerobic digestion, Bioresour. Technol. 192 (2015) 682-688. doi:10.1016/j.biortech.2015.06.034.

[10] S. Liu, F. Xu, X. Ge, Y. Li, Comparison between ensilage and fungal pretreatment for storage of giant reed and subsequent methane production, Bioresour. Technol. 209 (2016) 246-253. doi:10.1016/j.biortech.2016.02.129.

[11] E. Kreuger, I. Nges, L. Björnsson, Ensiling of crops for biogas production: effects on methane yield and total solids determination, Biotechnol. Biofuels. 4 (2011) 44. doi:10.1186/1754-6834-4-44.

[12] S. Menardo, P. Balsari, E. Tabacco, G. Borreani, Effect of Conservation Time and the Addition of Lactic Acid Bacteria on the Biogas and Methane Production of Corn Stalk Silage, Bioenergy Res. 8 (2015) 1810-1823. doi:10.1007/s12155015-9637-7.

[13] A. Lehtomäki, Biogas Production from Energy Crops and Crop Residues, (2006) $1-91$.

[14] R. Teixeira Franco, P. Buffière, R. Bayard, Optimizing agricultural wastes storage before anaerobic digestion : impact of ensiling on methane potential of lignocellulosic biomass, in: 4th Int. Conf. Sustain. Solid Waste Manag., Limassol, Cyprus, 2016. 
[15] R. Teixeira Franco, P. Buffière, R. Bayard, Co-ensiling of cattle manure before biogas production: effects of fermentation stimulants and inhibitors on biomass and methane preservation, Renew. Energy. (2018). doi:10.1016/j.renene.2018.01.035

[16] R. Teixeira Franco, P. Buffière, R. Bayard, Cattle manure for biogas production. Does ensiling and wheat straw addition enhance preservation of biomass and methane potential?, Biofuels. (2017). doi:10.1080/17597269.2017.1387751.

[17] M. Lou Hillion, R. Moscoviz, E. Trably, Y. Leblanc, N. Bernet, M. Torrijos, et al., Co-ensiling as a new technique for long-term storage of agro-industrial waste with low sugar content prior to anaerobic digestion, Waste Manag. 71 (2017) 147-155. doi:10.1016/j.wasman.2017.10.024.

[18] S.U. Larsen, K. Hjort-Gregersen, A.H. Vazifehkhoran, J.M. Triolo, Co-ensiling of straw with sugar beet leaves increases the methane yield from straw, Bioresour. Technol. 245 (2017) 106-115. doi:10.1016/j.biortech.2017.08.117.

[19] H.D.S.C. Neal, J.H.M. Thornley, A model of the anaerobic phase of ensiling, Grass Forage Sci. 38 (1983) 121-134. doi:10.1111/j.1365-2494.1983.tb01630.x.

[20] R.E. Pitt, R.E. Muck, R.Y. Leibensperger, A quantitative model of the ensilage process in lactate silages, Grass Forage Sci. 40 (1985) 279-303. doi:10.1111/j.1365-2494.1985.tb01755.x.

[21] B. Fezzani, R. Ben Cheikh, Implementation of IWA anaerobic digestion model No. 1 (ADM1) for simulating the thermophilic anaerobic co-digestion of olive mill wastewater with olive mill solid waste in a semi-continuous tubular digester, Chem. Eng. J. 141 (2008) 75-88. doi:10.1016/j.cej.2007.10.024.

[22] P. Rivas-García, J.E. Botello-Álvarez, A. Estrada-Baltazar, J.L. Navarrete- 
Bolaños, Numerical study of microbial population dynamics in anaerobic digestion through the Anaerobic Digestion Model No. 1 (ADM1), Chem. Eng. J. 228 (2013) 87-92. doi:10.1016/j.cej.2013.05.013.

[23] X.S. Shi, X.Z. Yuan, Y.P. Wang, S.J. Zeng, Y.L. Qiu, R.B. Guo, et al., Modeling of the methane production and $\mathrm{pH}$ value during the anaerobic co-digestion of dairy manure and spent mushroom substrate, Chem. Eng. J. 244 (2014) 258-263. doi:10.1016/j.cej.2014.02.007.

[24] D.J. Batstone, J. Keller, I. Angelidaki, S. V. Kalyuzhnyi, S.G. Pavlostathis, A. Rozzi, et al., Anaerobic Digestion Model No.1 (ADM1), IWA Publishing, London, 2002.

[25] C. Holliger, M. Alves, D. Andrade, I. Angelidaki, S. Astals, U. Baier, et al., Towards a standardization of biomethane potential tests, Water Sci. Technol. 74 (2016) 2515-2522. doi:10.2166/wst.2016.336.

[26] A. Bouguettoucha, B. Balannec, A. Amrane, Unstructured Models for Lactic Acid Fermentation - A Review, Food Technol. Biotechnol. 49 (2011) 3-12.

[27] W.A. Dewar, P. McDonald, R. Whittenbury, The hydrolysis of grass hemicelluloses during ensilage, J. Sci. Food Agric. 14 (1963) 411-417. doi:10.1002/jsfa.2740140610.

[28] G. Borreani, A. Revello, S. Colombini, M. Odoardi, R. Paoletti, E. Tabacco, Fermentative profiles of field pea (Pisum sativum), faba bean (Vicia faba) and white lupin (Lupinus albus) silages as affected by wilting and inoculation, Anim. Feed Sci. Technol. 151 (2009) 316-323. doi:10.1016/j.anifeedsci.2009.01.020.

[29] R. Le Hyaric, H. Benbelkacem, J. Bollon, R. Bayard, R. Escudié, P. Buffière, Influence of moisture content on the specific methanogenic activity of dry 
mesophilic municipal solid waste digestate, J. Chem. Technol. Biotechnol. 87 (2012) 1032-1035. doi:10.1002/jctb.2722.

[30] R. Le Hyaric, C. Chardin, H. Benbelkacem, J. Bollon, R. Bayard, R. Escudié, et al., Influence of substrate concentration and moisture content on the specific methanogenic activity of dry mesophilic municipal solid waste digestate spiked with propionate, Bioresour. Technol. 102 (2011) 822-827. doi:10.1016/j.biortech.2010.08.124.

[31] S.A.Z. Mahmoud, M.M. Zaki, E.A. Saleh, Factors affecting the microbial and chemical composition of silage: IV. Effect of wilting on maize silage, Zentralblatt Fuer Bakteriol. Parasitenkunde, Infekt. Und Hyg. Zweite Naturwissenschaftliche Abteilung Mikrobiol. Der Landwirtschaft, Der Technol. Und Des Umweltschutzes. 134 (1979) 34-39. doi:10.1016/S03236056(79)80061-0.

[32] J.M. Wilkinson, A laboratory evaluation of comfrey (Symphytum officinale L.) as a forage crop for ensilage, Anim. Feed Sci. Technol. 104 (2003) 227-233.

[33] M. Kamali, T. Gameiro, M.E. V. Costa, I. Capela, Anaerobic digestion of pulp and paper mill wastes - An overview of the developments and improvement opportunities, Chem. Eng. J. 298 (2016) 162-182. doi:10.1016/j.cej.2016.03.119.

[34] D.R. Lide, CRC Handbook of Chemistry and Physics, Internet Version, CRC Press, Boca Raton, FL, 2005. http://www.hbcpnetbase.com. 
Table 1 - Examples of chemical pathway for LAB and clostridial fermentation

\begin{tabular}{ccc}
\hline Reaction & Possible pathway & Consequence \\
\hline $\begin{array}{c}\text { Homofermentative } \\
\text { lactic acid fermentation }\end{array}$ & $\mathrm{C}_{6} \mathrm{H}_{12} \mathrm{O}_{6} \rightarrow 2 \mathrm{C}_{3} \mathrm{H}_{6} \mathrm{O}_{3}$ & $\begin{array}{c}\mathrm{pH} \text { decrease; } \\
\text { conservation of } \\
\text { organic matter }\end{array}$ \\
\hline $\begin{array}{c}\text { Saccharolytic } \\
\text { clostridial fermentation }\end{array}$ & $2 \mathrm{C}_{3} \mathrm{H}_{6} \mathrm{O}_{3} \rightarrow \mathrm{C}_{4} \mathrm{H}_{8} \mathrm{O}_{2}+2 \mathrm{CO}_{2}+2 \mathrm{H}_{2}$ & $\begin{array}{c}\mathrm{pH} \text { increase; } \\
\text { increase of biomass } \\
\text { activity/degradation }\end{array}$
\end{tabular}


Table 2 - Raw materials and experimental ensiling conditions.

\begin{tabular}{cccccc}
\hline Feedstock & Treatment & Nomenclature & $\mathbf{p H}$ & TS (\%) & WSC $\left(\mathbf{k g}_{\mathbf{C O D}} \cdot \mathbf{m}^{-3}\right)$ \\
\hline \multirow{2}{*}{ Catch crop } & Fresh & CC-Fresh & 6.35 & 10.1 & 12.0 \\
\cline { 2 - 6 } & & & & & 31.8 \\
\hline \multirow{2}{*}{ Cattle manure } & Fresh & CM-Fresh & 8.26 & 19.2 & 0 \\
\cline { 2 - 6 } & Glucose & CM-Glucose & 7.91 & 24.9 & 129.0 \\
\hline
\end{tabular}


Table 3 - Rate coefficients and kinetic rate equations involved in biochemical reactions.

\begin{tabular}{|c|c|c|c|c|c|c|c|c|c|c|c|c|c|c|c|c|c|c|}
\hline \multicolumn{2}{|r|}{ Component (i) $\rightarrow$} & 1 & 2 & 3 & 4 & 5 & 6 & 7 & 8 & 9 & 10 & 11 & 12 & 13 & 14 & 15 & 16 & \multirow{2}{*}{ Rate, $\rho_{j}\left(\mathbf{k g}_{\mathrm{COD}} \cdot \mathbf{m}^{-3} \mathbf{j}^{-1}\right)$} \\
\hline \multicolumn{2}{|c|}{ (j) Process $\downarrow$} & $X_{C H}$ & $S_{C H}$ & $S_{L A}$ & $S_{E T}$ & $X_{S U}$ & $S_{B A}$ & $S_{A C}$ & $S_{H 2}$ & $S_{I C}$ & $X_{L A}$ & $X_{P R}$ & $S_{A A}$ & $S_{I N}$ & $X_{A A}$ & $S_{\mathrm{CH} 4}$ & $X_{A C}$ & \\
\hline 1 & $\begin{array}{l}\text { Hydrolysis of } \\
\text { carbohydrates }\end{array}$ & -1 & 1 & & & & & & & & & & & & & & & $k_{1} X_{C H}$ \\
\hline 2 & $\begin{array}{l}\text { Lactic } \\
\text { fermentation }\end{array}$ & & -1 & $\begin{array}{l}(1 \\
\left.-Y_{S U}\right) \\
\times f_{L A, C H}\end{array}$ & $\begin{array}{l}(1 \\
\left.-Y_{S U}\right) \\
\times f_{E T, C H}\end{array}$ & $Y_{S U}$ & & & & & & & & & & & & $\frac{X_{S U} \mu_{\max _{-} S U}}{Y_{S U}} \frac{S_{C H}}{K_{S_{-} S U}+S_{C H}} \frac{\left(p H / p_{M_{S} S U}\right)^{q_{S U}}}{1+\left(p H / p_{M_{-} S U}\right)^{q_{S U}}}$ \\
\hline 3 & $\begin{array}{l}\text { Clostridial } \\
\text { fermentation }\end{array}$ & & & -1 & & & $\begin{array}{l}(1 \\
\left.-Y_{L A}\right) \\
\times f_{B A, L A}\end{array}$ & $\begin{array}{l}(1 \\
\left.-Y_{L A}\right) \\
\times f_{A C, L A}\end{array}$ & $\begin{array}{c}(1- \\
\left.Y_{L A}\right) \times \\
f_{H 2, L A}\end{array}$ & $\frac{1-Y_{L A}}{96}$ & $Y_{L A}$ & & & & & & & $\frac{X_{L A} \mu_{m a} L A}{Y_{L A}} \frac{S_{L A}}{K_{S_{-} L A}+S_{L A}} \frac{\left(p H / p_{M_{L} L A}\right)^{q_{L A}}}{1+\left(p H / p_{M_{-} L A}\right)^{q_{L A}}}$ \\
\hline 4 & $\begin{array}{l}\text { Hydrolysis of } \\
\text { proteins }\end{array}$ & & & & & & & & & & & -1 & 1 & & & & & $k_{4} X_{P R}$ \\
\hline 5 & $\begin{array}{l}\text { Fermentation of } \\
\text { amino acids }\end{array}$ & & & & & & $\begin{array}{l}(1 \\
\left.-Y_{A A}\right) \\
\times f_{B A, A A}\end{array}$ & $\begin{array}{l}(1 \\
\left.-Y_{A A}\right) \\
\times f_{A C, A A}\end{array}$ & $\begin{array}{l}(1 \\
\left.-Y_{A A}\right) \\
\times f_{H 2, A A}\end{array}$ & & & & -1 & $N_{A A}$ & $Y_{A A}$ & & & $\frac{X_{A A} \mu_{\max \_A A}}{Y_{A A}} \frac{S_{A A}}{K_{S_{-} A A}+S_{A A}} \frac{\left(p H / p_{M_{A} A A}\right)^{q_{A A}}}{1+\left(p H / p_{M_{-} A A}\right)^{q_{A A}}}$ \\
\hline 6 & Methanogenesis & & & & & & & -1 & & $\frac{1-Y_{A C}}{64}$ & & & & & & $\begin{array}{l}1- \\
Y_{A C}\end{array}$ & $Y_{A C}$ & $\frac{X_{A C} \mu_{\text {max } A C}}{Y_{A C}} \frac{S_{A C}}{K_{S_{-} A C}+S_{A C}} \frac{\left(p H / p_{M_{-A C}}\right)^{q_{A C}}}{1+\left(p H / p_{M_{-} A C}\right)^{q_{A C}}}$ \\
\hline & & 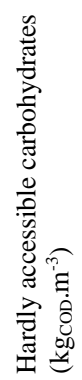 & 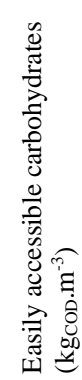 & 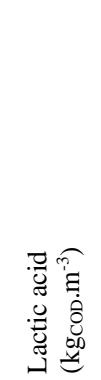 & 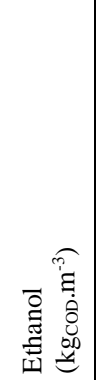 & 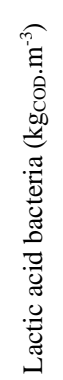 & 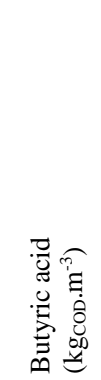 & 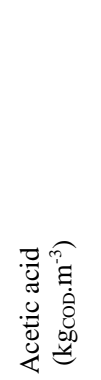 & 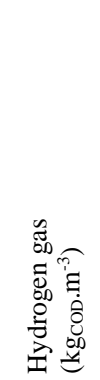 & 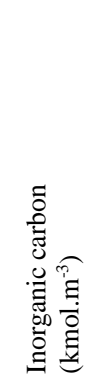 & 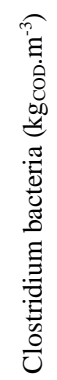 & 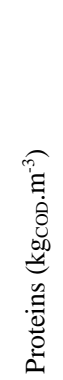 & 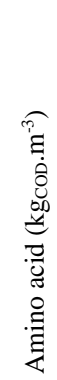 & 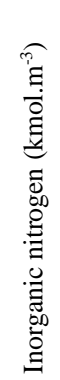 & 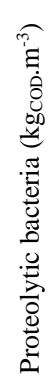 & 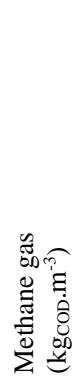 & 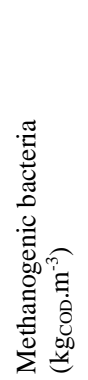 & \\
\hline
\end{tabular}


Table 4 - Acid-base equilibrium constants $\left(25^{\circ} \mathrm{C}\right)$ [34].

\begin{tabular}{ccc}
\hline Acid/base pair & $\mathbf{p K}_{\mathbf{a}}$ & $\mathbf{K}_{\mathbf{a}}$ \\
\hline $\mathrm{CO}_{2} / \mathrm{HCO}_{3}^{-}$ & 6.35 & $4.47 \times 10^{-7}$ \\
$\mathrm{H}_{2} \mathrm{O} /\left(\mathrm{OH}^{-}+\mathrm{H}^{+}\right)$ & 13.995 & $1.01 \times 10^{-14}$ \\
$\mathrm{HBA} / \mathrm{BA}^{-}$ & 4.83 & $1.48 \times 10^{-5}$ \\
$\mathrm{HAC} / \mathrm{AC}^{-}$ & 4.756 & $1.75 \times 10^{-5}$ \\
$\mathrm{HLA} / \mathrm{LA}^{-}$ & 3.86 & $1.38 \times 10^{-4}$ \\
$\mathrm{NH}_{4}^{+} / \mathrm{NH}_{3}$ & 9.25 & $5.62 \times 10^{-10}$ \\
\hline
\end{tabular}


Table 5 - Initial state variables for the tested raw materials. Concentrations are expressed in $\mathrm{kg}_{\mathrm{COD}} \cdot \mathrm{m}^{-3}$ except for inorganic carbon/nitrogen $\left(\mathrm{kmol} \cdot \mathrm{m}^{-3}\right)$.

\section{Condition}

\begin{tabular}{|c|c|c|c|c|}
\hline \multirow[t]{2}{*}{ State variable } & \multicolumn{2}{|c|}{ Catch crop } & \multicolumn{2}{|c|}{ Cattle manure } \\
\hline & CC-Fresh & CC-Wilted & CM-Fresh & CM-Glucose \\
\hline$X_{C H}$ & 30.0 & 235 & 205 & 227 \\
\hline$S_{C H}$ & 44.0 & 74.0 & 9.00 & 170 \\
\hline$S_{L A}$ & 0.0 & 0.0 & 0.0 & 0.0 \\
\hline$S_{E T}$ & 0.0 & 0.254 & 0.0 & 0.0 \\
\hline$X_{S U}$ & 0.142 & 0.208 & 0.142 & 0.155 \\
\hline$S_{B A}$ & 0.0 & 0.0 & 0.0 & 0.0 \\
\hline$S_{A C}$ & 0.541 & 0.848 & 13.8 & 7.13 \\
\hline$S_{H 2}$ & 0.0 & 0.0 & 0.0 & 0.0 \\
\hline$S_{I C}$ & 0.00735 & 0.00735 & 0.00735 & 0.00735 \\
\hline$X_{L A}$ & 0.142 & 0.208 & 0.142 & 0.155 \\
\hline$X_{P R}$ & 28.0 & 160 & 24.3 & 27.6 \\
\hline$S_{A A}$ & 5.00 & 13.0 & 3.50 & 9.97 \\
\hline$S_{I N}$ & 0.00912 & 0.101 & 0.0547 & 0.0586 \\
\hline$X_{A A}$ & 0.142 & 0.208 & 0.142 & 0.155 \\
\hline$S_{C H 4}$ & 0.0 & 0.0 & 0.0 & 0.0 \\
\hline$X_{A C}$ & 0.142 & 0.208 & 0.142 & 0.155 \\
\hline
\end{tabular}


Table 6 - Fixed kinetic and stoichiometric parameters based on literature data.

\begin{tabular}{cccc}
\hline Parameter & Unit & Value & Reference \\
\hline$Y_{S U}$ & & 0.265 & {$[19]$} \\
$Y_{L A}$ & $\mathrm{~kg}_{\mathrm{COD} \cdot \mathrm{kg}_{\mathrm{COD}}{ }^{-1}}$ & 0.265 & {$[19]$} \\
$Y_{A A}$ & & 0.265 & {$[19]$} \\
$Y_{A C}$ & & 0.055 & {$[19]$} \\
$K_{S_{-} S U}$ & & 0.1 & {$[19,26]$} \\
$K_{S_{-} L A}$ & $\mathrm{~kg}_{\mathrm{COD} \cdot \mathrm{m}^{-3}}$ & 0.1 & {$[19,26]$} \\
$K_{S_{-} A A}$ & & 0.1 & {$[19,26]$} \\
$K_{S_{-} A C}$ & & 0.1 & {$[19,26]$} \\
\hline$N_{A A}$ & $\mathrm{kmol}$ & $0.007 \mathrm{~kg}_{\mathrm{COD}}{ }^{-1}$ & {$[24]$} \\
\hline
\end{tabular}


Table 7 - Suggested values for the kinetic and stoichiometric parameters optimized during simulations.

\begin{tabular}{|c|c|c|c|c|c|}
\hline \multirow{3}{*}{ Parameter } & \multirow{3}{*}{ Unit } & \multicolumn{4}{|c|}{ Condition } \\
\hline & & \multicolumn{2}{|c|}{ Catch crop } & \multicolumn{2}{|c|}{ Cattle manure } \\
\hline & & CC-Fresh & CC-Wilted & CM-Fresh & CM-Glucose \\
\hline$k_{1}$ & \multirow{2}{*}{$d^{-1}$} & 0.002 & 0.0033 & 0.004 & 0.002 \\
\hline$k_{4}$ & & 0.012 & 0.0017 & 0.0005 & 0.0005 \\
\hline$\mu_{\text {max_SU }}$ & \multirow{4}{*}{$d^{-1}$} & 0.72 & 0.65 & $>0.85^{1}$ & 0.71 \\
\hline$\mu_{\max \_L A}$ & & 0.84 & 0.60 & $>0.65^{1}$ & 0.70 \\
\hline$\mu_{\max \_A A}$ & & 0.56 & 0.58 & 0.23 & 0.23 \\
\hline$\mu_{\text {max } \_A C}$ & & 0.54 & $<0.46^{2}$ & 0.394 & $<0.22^{2}$ \\
\hline$p_{M \_} S U$ & \multirow{4}{*}{-} & 4.3 & 4.3 & 4.3 & 4.3 \\
\hline$p_{M_{-} L A}$ & & 5.5 & 5.5 & 5.5 & 5.5 \\
\hline$p_{M_{-} A A}$ & & 5.5 & 5.5 & 5.5 & 5.5 \\
\hline$p_{M_{-} A C}$ & & 7.0 & 7.0 & 7.0 & 7.0 \\
\hline$q_{S U}$ & & 35 & 35 & 35 & 35 \\
\hline$q_{L A}$ & & 12 & 12 & 12 & 12 \\
\hline$q_{A A}$ & & 12 & 12 & 12 & 12 \\
\hline $\boldsymbol{q}_{A C}$ & & 12 & 12 & 12 & 12 \\
\hline$\overline{f_{L A, C H}}$ & \multirow{8}{*}{$\begin{array}{l}\mathrm{kg}_{\mathrm{COD}} \cdot \\
\mathrm{kg}_{\mathrm{COD}}{ }^{-1}\end{array}$} & 0.92 & 0.92 & 1.00 & 1.00 \\
\hline$f_{E T, C H}$ & & 0.08 & 0.08 & 0.00 & 0.00 \\
\hline$f_{B A, L A}$ & & 0.54 & 0.54 & 0.33 & 0.33 \\
\hline$f_{A C, L A}$ & & 0.29 & 0.29 & 0.50 & 0.50 \\
\hline$f_{H 2, L A}$ & & 0.17 & 0.17 & 0.17 & 0.17 \\
\hline$f_{A C, A A}$ & & 0.88 & 0.88 & 0.88 & 0.88 \\
\hline$f_{B A, A A}$ & & 0.06 & 0.06 & 0.06 & 0.06 \\
\hline$f_{H 2, A A}$ & & 0.06 & 0.06 & 0.06 & 0.06 \\
\hline
\end{tabular}

1,2 The exact values were not determined with the experimental results since reactions either occurred before 7 days of storage ${ }^{1}$ or were not significant until the end of ensiling ${ }^{2}$. 


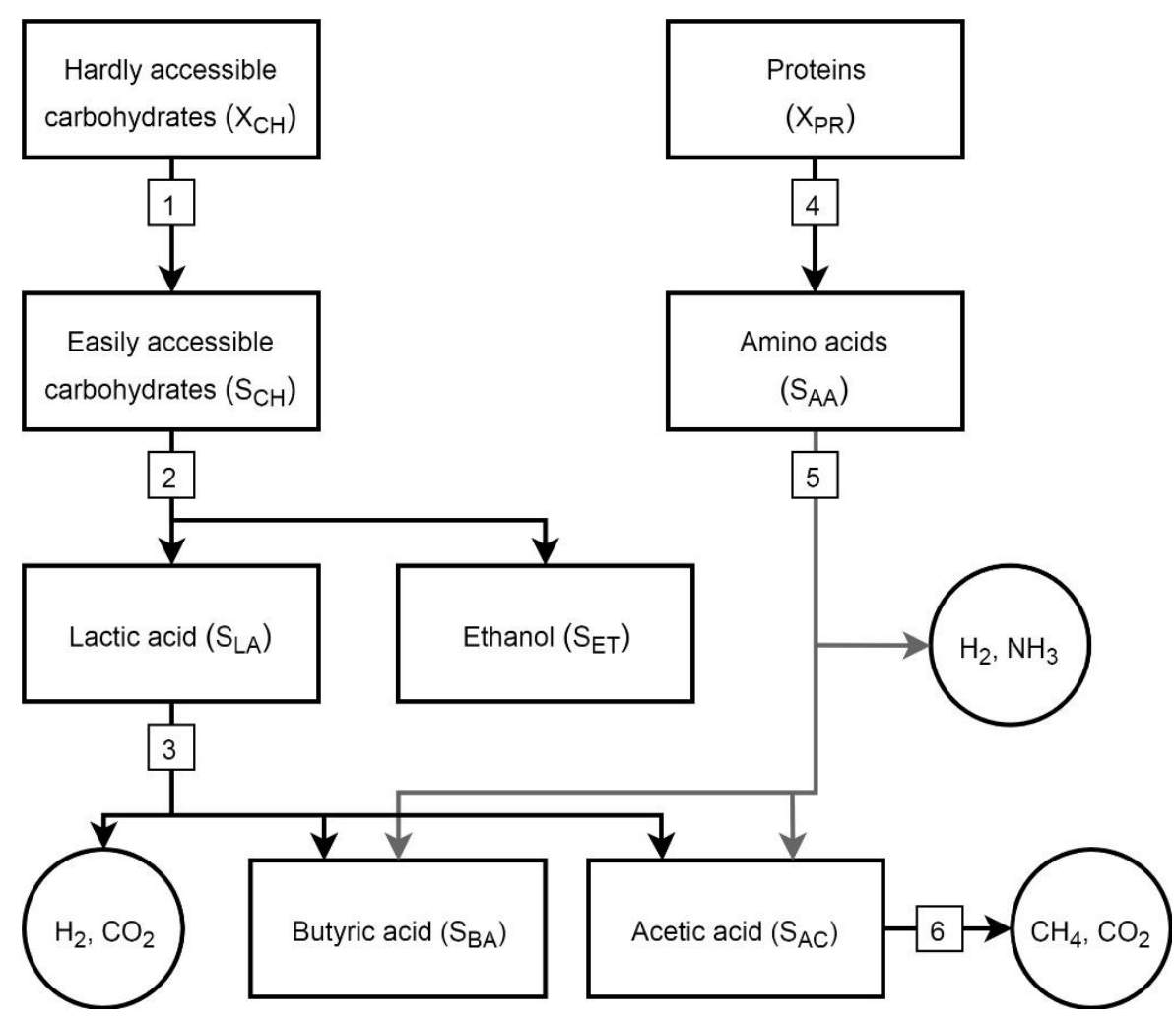

Figure 1 - Structure of the ensiling model - anaerobic phase. (1) Hydrolysis of carbohydrates; (2) Lactic fermentation; (3) Clostridial fermentation; (4) Hydrolysis of proteins; (5) Fermentation of amino acids; (6) Methanogenesis. 


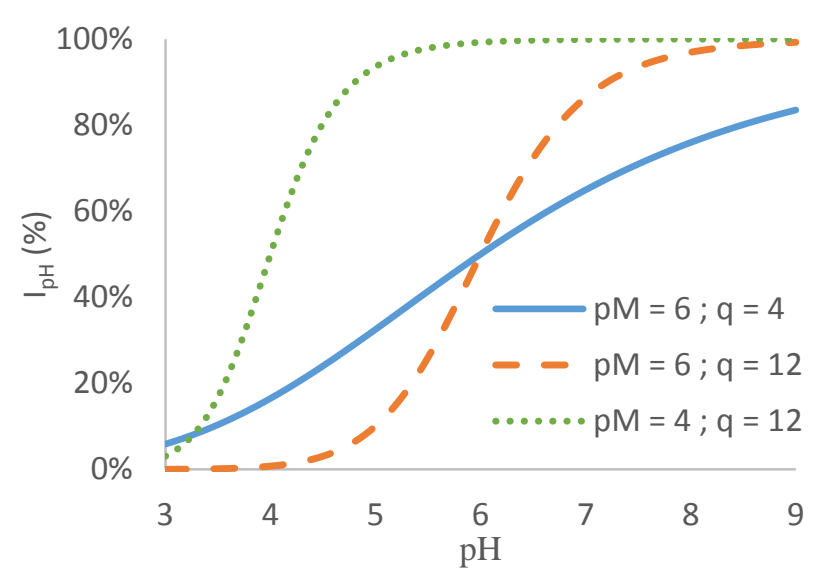

Figure 2 - Variation of the $\mathrm{pH}$ inhibition function $\left(I_{p H}=\frac{\left(p H / p_{M}\right)^{q}}{1+\left(p H / p_{M}\right)^{q}}\right)$ with the parameters $p_{M}$ and $q$. 
(A)

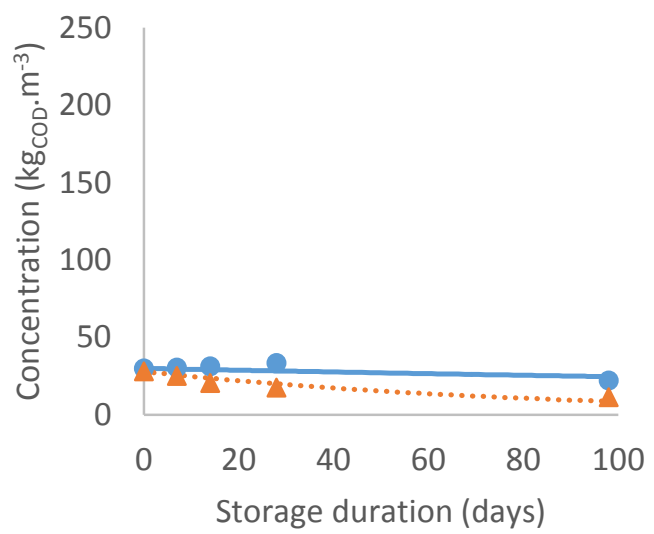

(C)

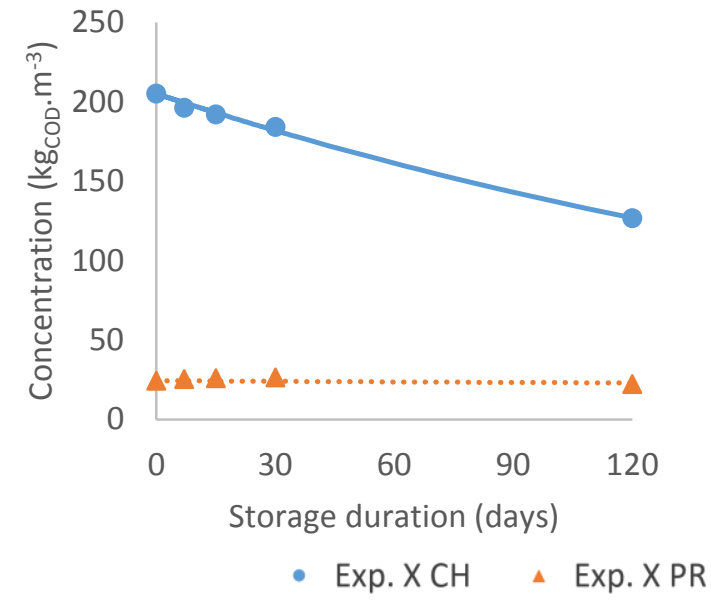

(B)

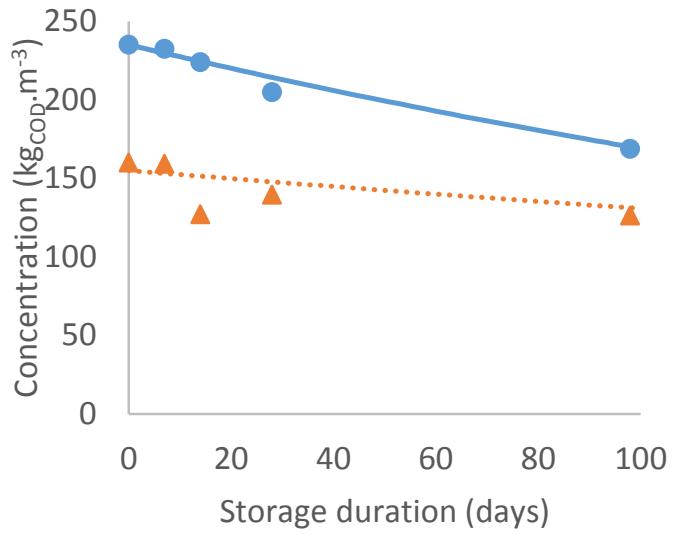

(D)

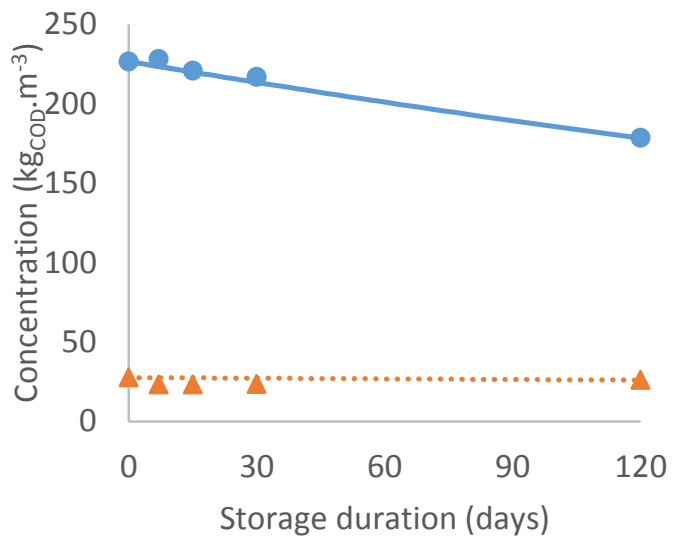

- Sim. X CH $\quad$...... Sim. X PR

Figure 3 - Simulations and experimental data for the evolution of hardly accessible fractions ( $\mathrm{X}_{\mathrm{CH}}$ and $\left.\mathrm{X}_{\mathrm{PR}}\right)$ of (A) CC-Fresh; (B) CC-Wilted; (C) CM-Fresh; (D) CMGlucose. 
(A)

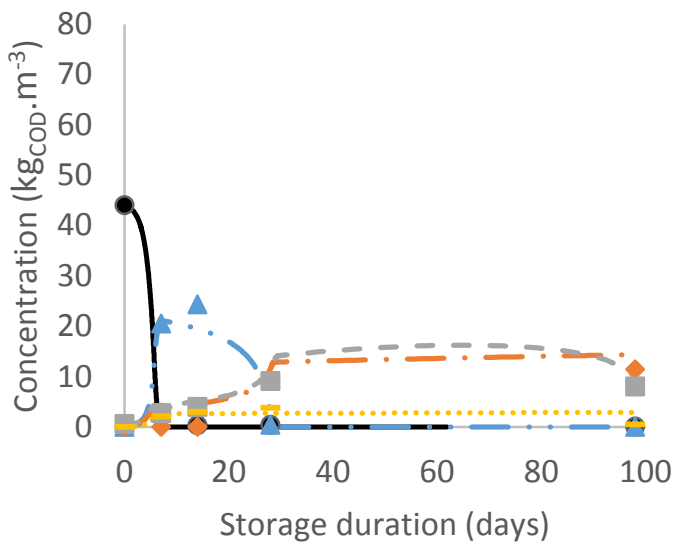

(C)

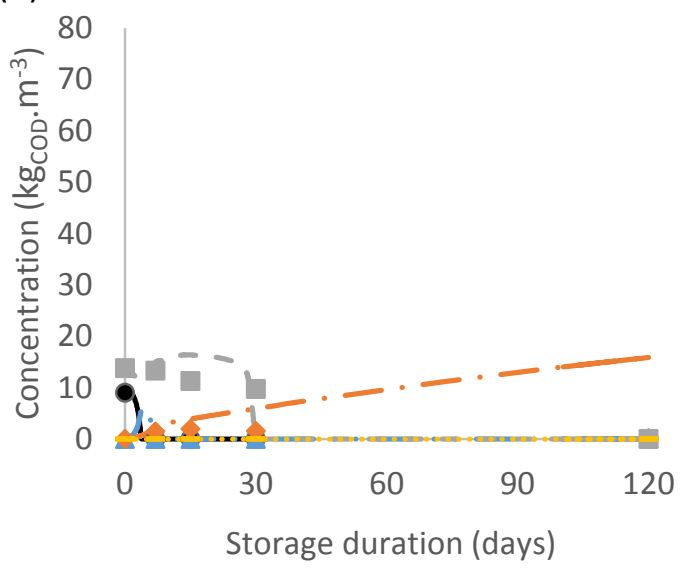

(B)

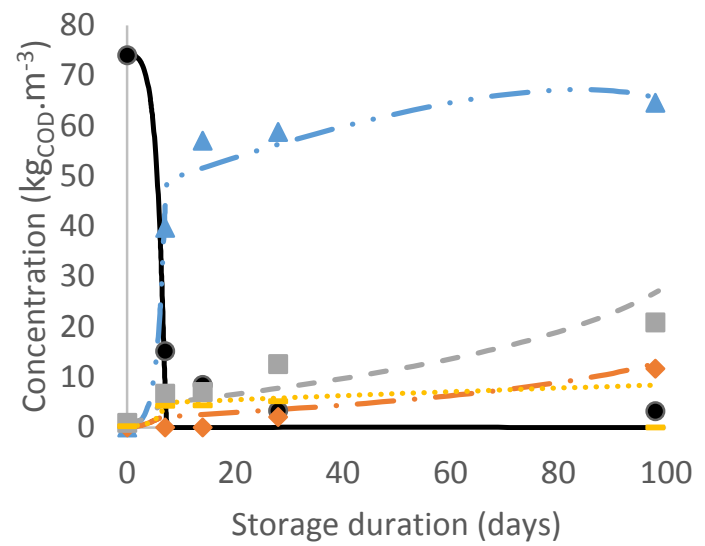

(D)

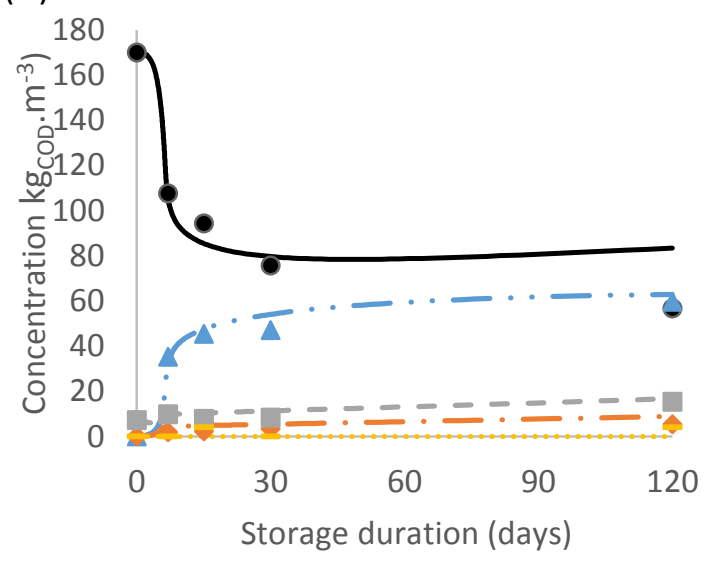

- Exp.SCH $\triangle$ Exp.SLA - Exp.SBA - Exp.SAC - Exp.SET

- Sim. SCH - Sim. S LA - Sim. SBA - - Sim. SAC …......Sim. SET

Figure 4 - Simulations and experimental data for the evolution of easily accessible

fractions $\left(\mathrm{S}_{\mathrm{CH}}, \mathrm{S}_{\mathrm{LA}}, \mathrm{S}_{\mathrm{ET}}, \mathrm{S}_{\mathrm{BA}}\right.$ and $\mathrm{S}_{\mathrm{AC}}$ ) of (A) CC-Fresh; (B) CC-Wilted; (C) CM-Fresh;

(D) CM-Glucose (presented on a larger scale). 
(A)

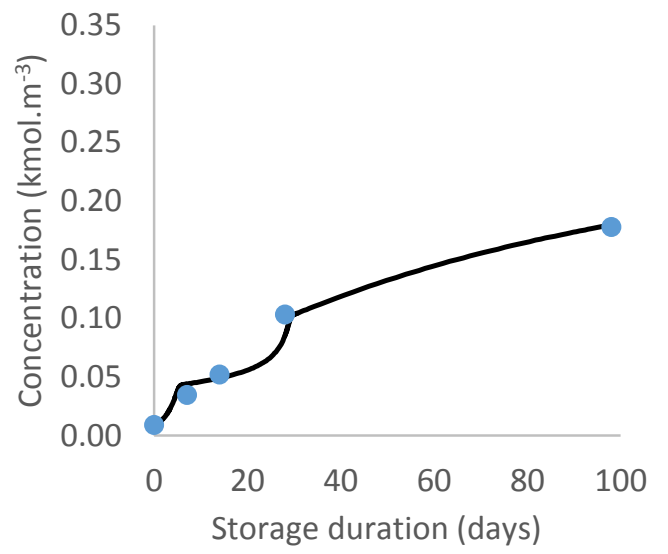

(C)

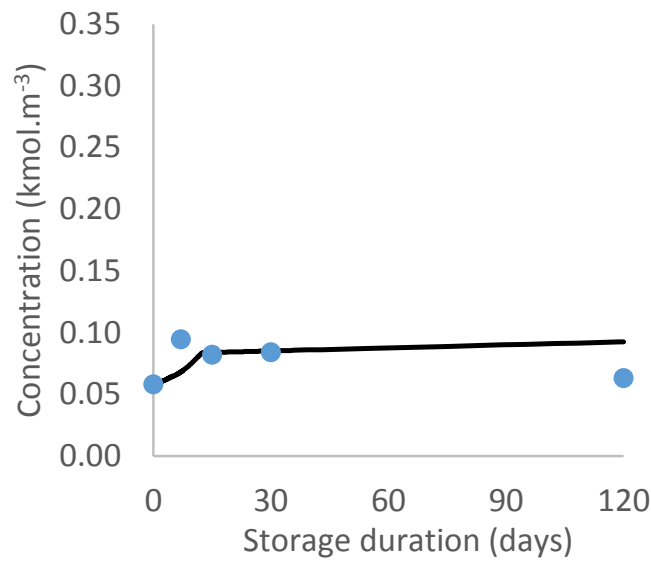

- Simulation
(B)

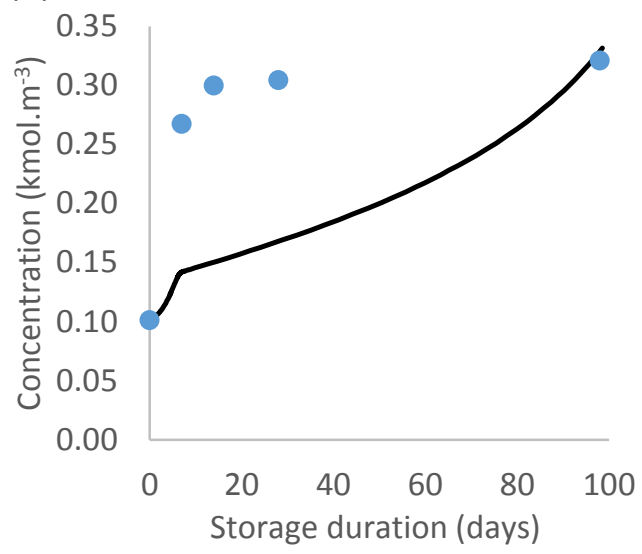

(D)

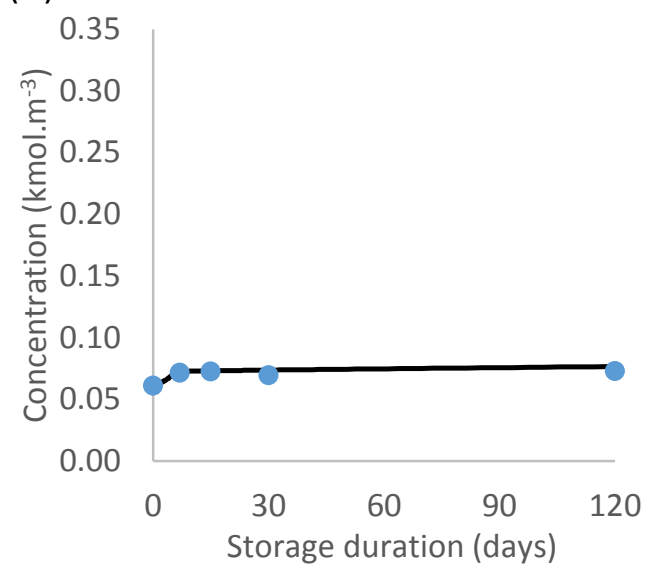

- Experimental

Figure 5 - Simulations and experimental data for the evolution of inorganic nitrogen ( $\left.\mathrm{S}_{\mathrm{IN}}\right)$ of (A) CC-Fresh; (B) CC-Wilted; (C) CM-Fresh; (D) CM-Glucose. 

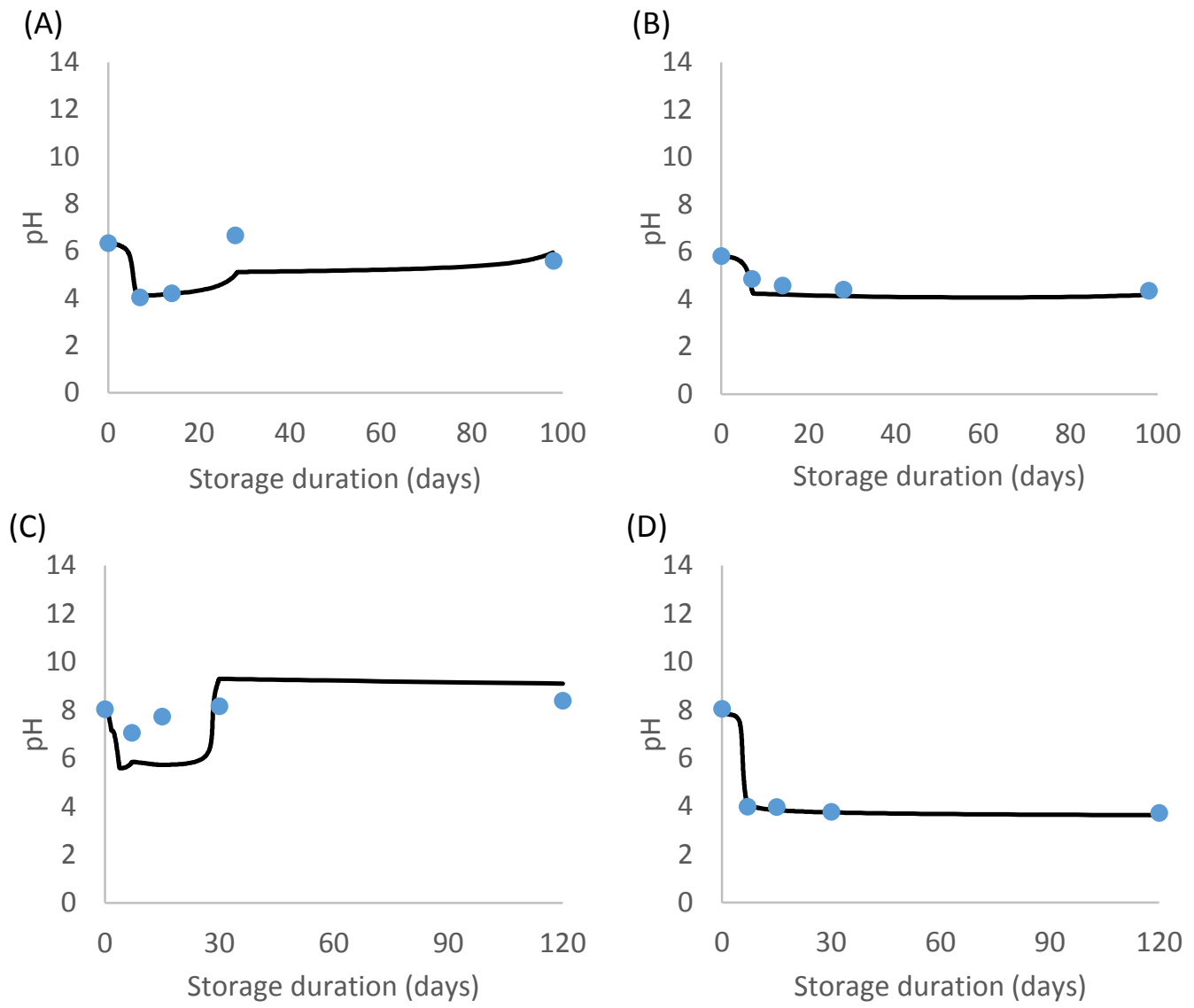

(D)

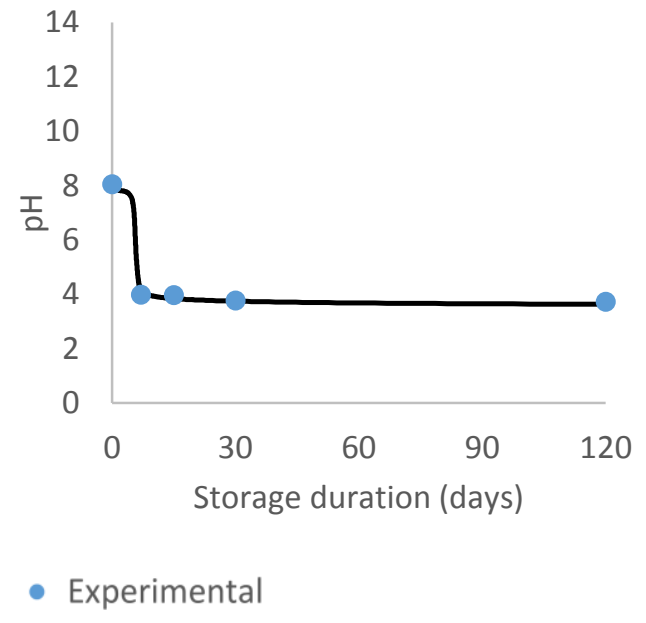

Figure 6 - Simulations and experimental data for the $\mathrm{pH}$ evolution of (A) CC-Fresh; (B) CC-Wilted; (C) CM-Fresh; (D) CM-Glucose. 
(A)

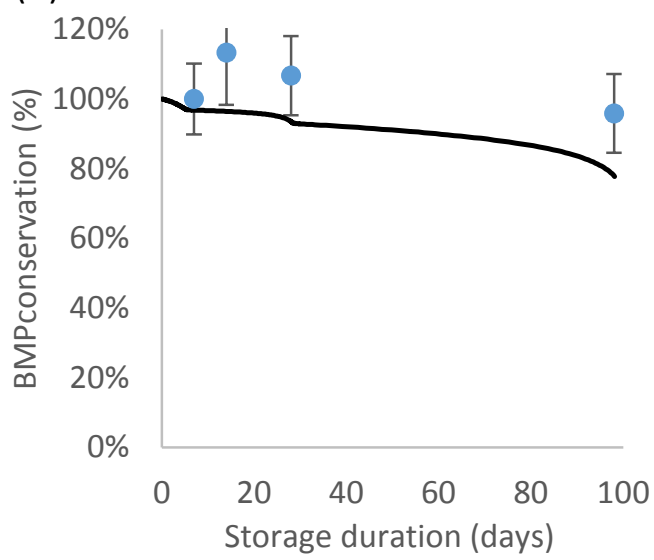

(C)

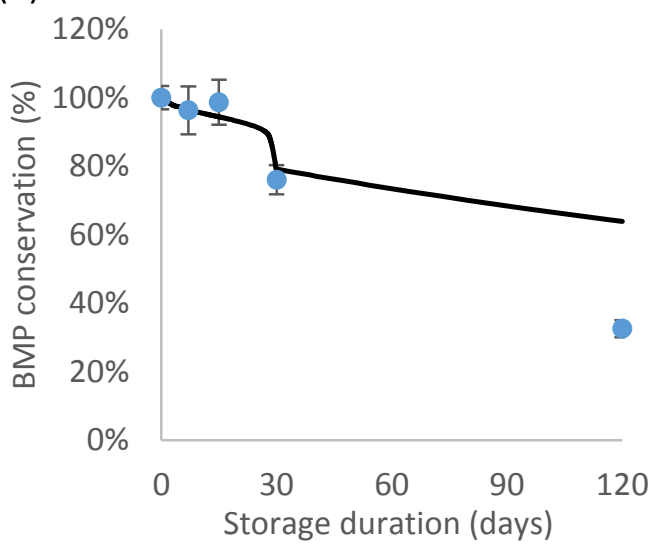

- Simulation
(B)

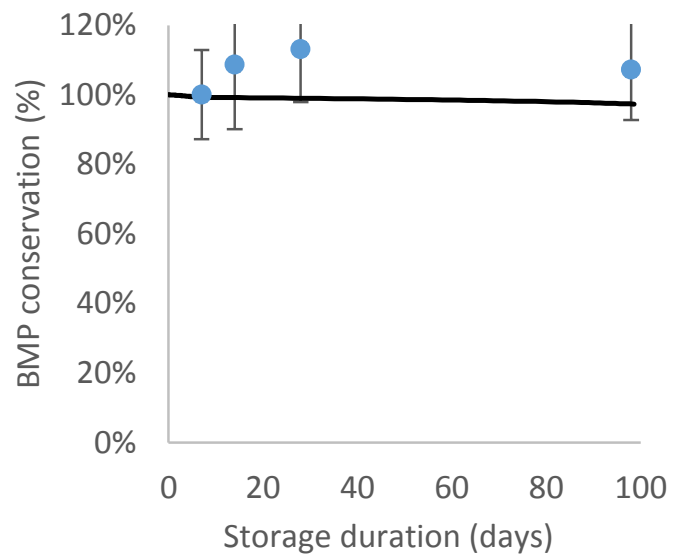

(D)

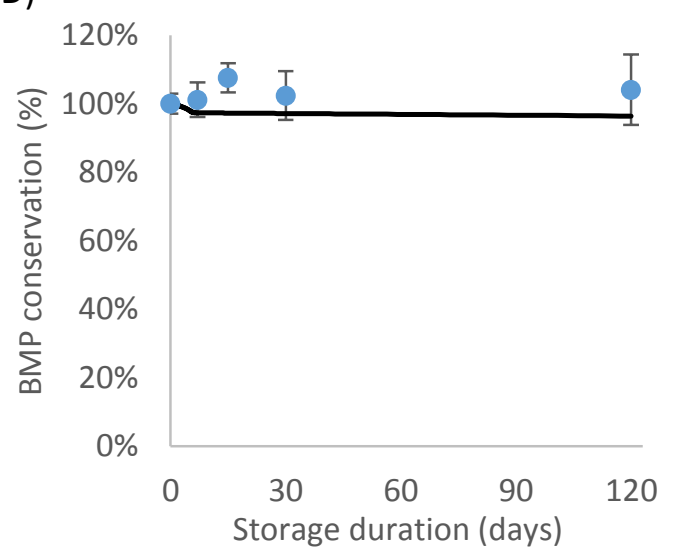

- Experimental

Figure 7 - Simulations and experimental data for the evolution of BMP conservation of (A) CC-Fresh; (B) CC-Wilted; (C) CM-Fresh; (D) CM-Glucose. Experimental data with energy conservation above $100 \%$ indicates an increase of BMP during ensiling. 


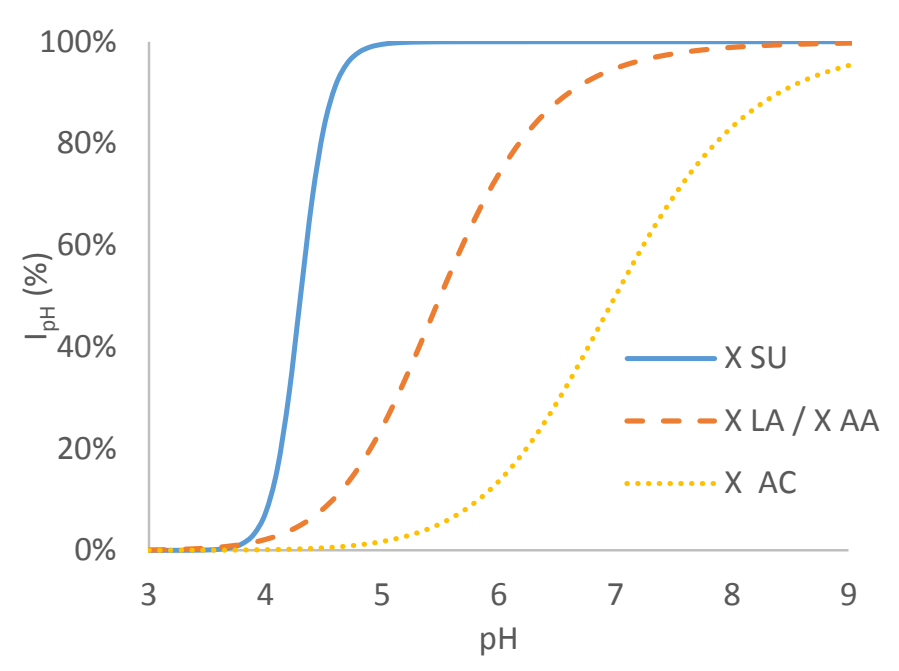

Figure 8 - Inhibition function based on the $\mathrm{pH}$ of the medium for the bacterial trophic groups of the model $\left(X_{S U}, X_{L A}, X_{A A}\right.$ and $\left.X_{A C}\right)$. 